\title{
Situational analysis of the private sector in the delivery of family planning services in Egypt: Current status and potential for increased involvement
}

\author{
Nahla G. Abdel-Tawab \\ Population Council \\ Doaa Oraby \\ Population Council \\ Benjamin Bellows \\ Population Council
}

Follow this and additional works at: https://knowledgecommons.popcouncil.org/departments_sbsr-rh

Part of the Demography, Population, and Ecology Commons, Family, Life Course, and Society Commons, and the International Public Health Commons How does access to this work benefit you? Let us know!

\section{Recommended Citation}

Abdel-Tawab, Nahla G., Doaa Oraby, and Benjamin Bellows. 2016. "Situational analysis of the private sector in the delivery of family planning services in Egypt: Current status and potential for increased involvement." Washington, DC: Population Council, The Evidence Project. 


\section{Evidence}

Situational Analysis of the Private

Sector in the Delivery of Family

Planning Services in Egypt:

Current Status and Potential for

Increased Involvement

Nahla Abdel-Tawab, Senior Associate \& Country Director, Population Council Doaa Oraby, Program Officer, Population Council Ben Bellows, Associate II, Population Council

MAY 2016

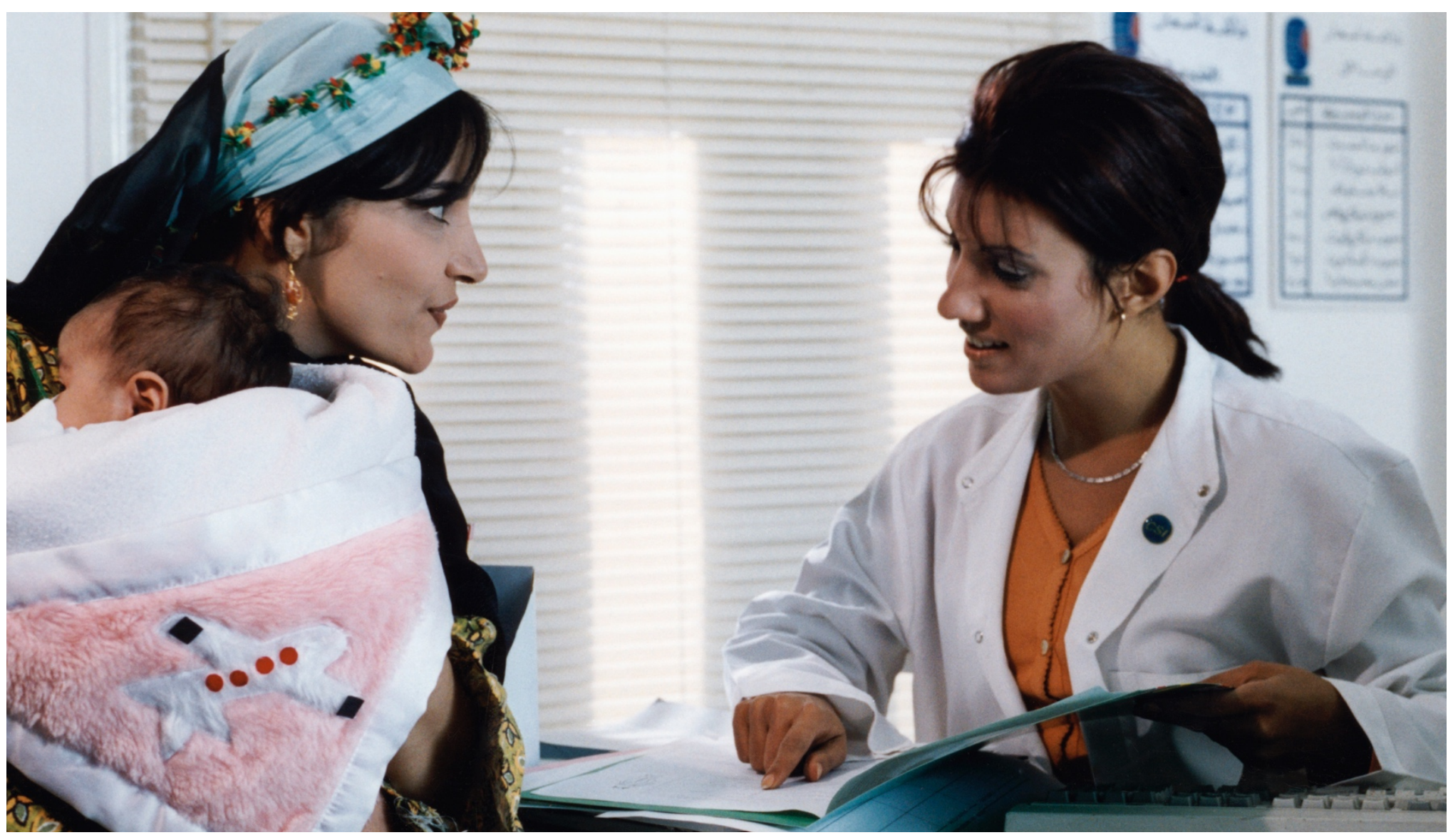




\section{The Evidence Project}

Population Council

4301 Connecticut Avenue, NW, Suite 280

Washington, DC 20008 USA

tel +12022379400

evidenceproject.popcouncil.org

The Evidence Project is made possible by the generous support of the American people through the United States Agency for International Development (USAID) under the terms of cooperative agreement no. AID-OAA-A-13-00087.

The contents of this document are the sole responsibility of the Evidence Project and Population Council and do not necessarily reflect the views of USAID or the United States Government.

Published in May 2016.

Suggested citation: Abdel-Tawab, Nahla, Doaa Oraby, and Ben Bellows. 2016. "Situational Analysis of the Private Sector in the Delivery of Family Planning Services in Egypt: Current Status and Potential for Increased Involvement," Research Report. Washington, DC: Population Council, The Evidence Project.

Photo credit on cover page (C) 2003 Center for Communication Programs, Courtesy of Photoshare

(C) 2016 The Population Council, Inc. 


\section{Table of Contents}

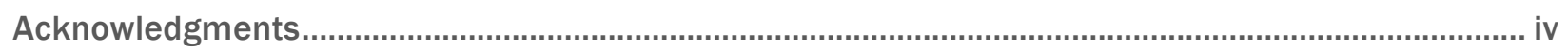

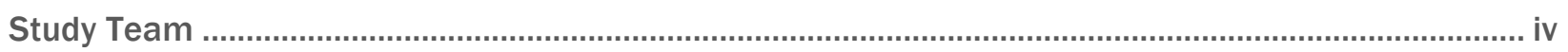

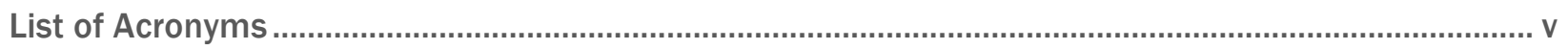

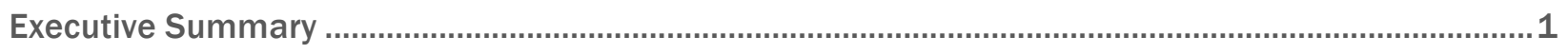

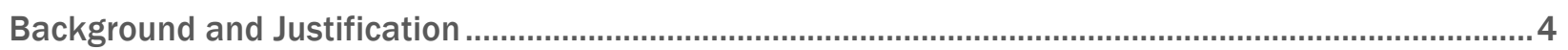

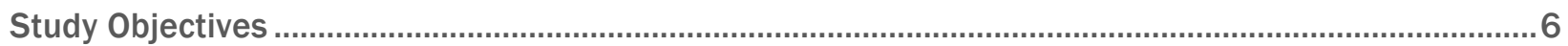

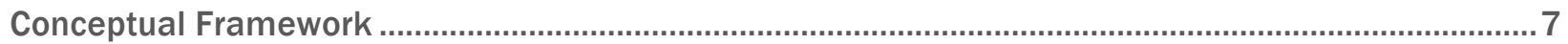

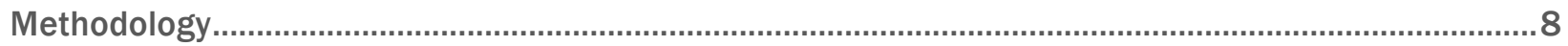

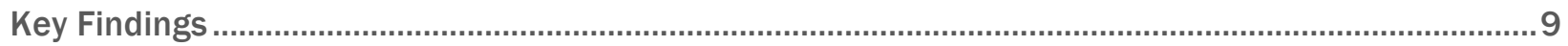

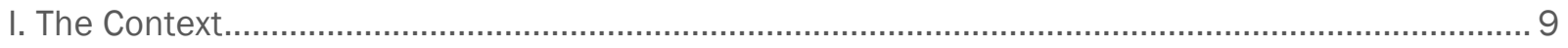

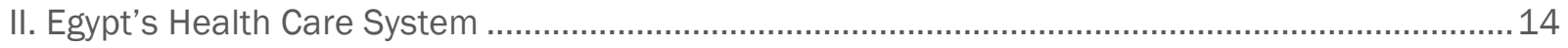

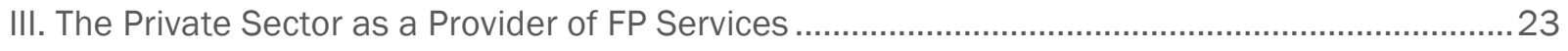

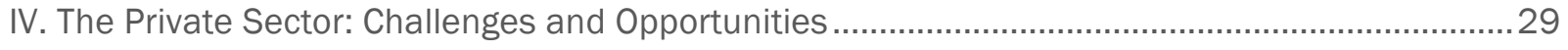

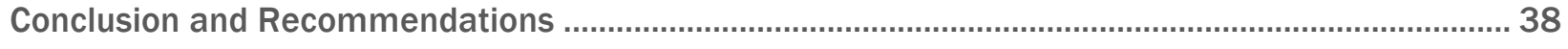

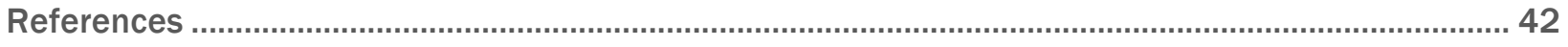

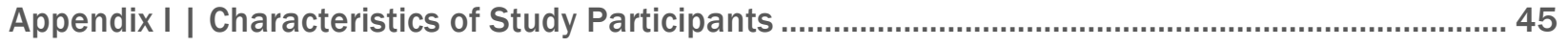

Appendix II | Buying and Selling Prices of Contraceptives Sold at Public Sector ............................... 46

Appendix III | List of Contraceptive Methods Available at Public, Private and NGO

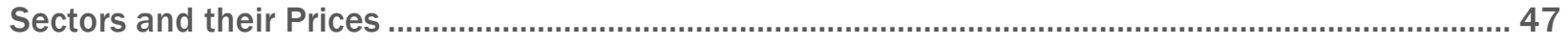

Appendix IV | Brands of FP Methods Available at Commercial Sectors and Their Prices................ 48

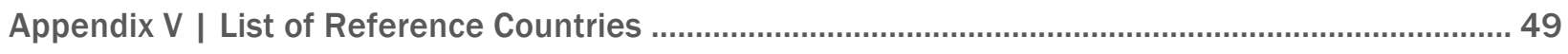




\section{List of Figures}

Figure 1 | Conceptual Framework of the Private Sector in FP Service Delivery ....................................7

Figure 2 | Trends in Use of the Private Sector as a Source of Modern Family Planning Methods

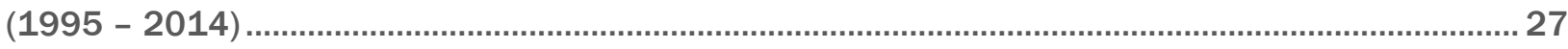

Figure 3 | Trends in Source of Family Planning Methods (1995 - 2014) ....................................... 28

Figure 4 | Trends in Use of NGOs as a Family Planning Methods Source, by Type of Method $(1995-2014)$

\section{List of Tables}

Table 1 | Percent Distribution of Source of FP Method by Selected Characteristics of Women....... 24

Table 2 | Trends in Family Planning Method Mix (1995 - 2014) ....................................................... 27

Table 3 | Need and Demand for Family Planning Among Currently Married Women....................... 33

Table 4 | Percentage of Women and Men Age 15 - 49 Who Know a Family Planning Method, by

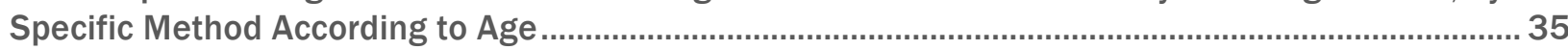




\title{
Acknowledgments
}

We are grateful to all of the individuals and organizations that made this study possible. We wish to thank members of the Advisory Committee for their supportive guidance throughout implementation of this study. We also wish to thank USAID for their financial support of this study and their valuable insights on the proposal and earlier drafts of the final report. Special thanks are due to the study participants, who openly shared their views and personal experiences, and to our consultants and interviewers for their competent assistance in collecting and analyzing data for this study.

We hope the study results will contribute to policies and programs that assist more couples in Egypt in achieving their fertility goals.

\section{Study Team}

\section{POPULATION COUNCIL/EGYPT}

\author{
Dr. Nahla Abdel-Tawab Country Director \\ Dr. Doaa Oraby $\quad$ Program Officer, Reproductive Health \\ Mr. Tarek Alam Eldin Implementation and Legal Officer \\ Ms. Gihan Hosny $\quad$ Program Administration Officer
}

\section{EVIDENCE PROJECT}
Dr. Karen Hardee Senior Associate and Evidence Project Director
Dr. Laura Reichenbach Senior Associate and Deputy Technical Director, Evidence Project
Dr. Ben Bellows Associate II, Evidence Project
Ms. Julia Adams Deputy Director for Administration, Evidence Project

\section{CONSULTANTS}
Ms. Elham Fateem
Development and Capacity Building Expert
Dr. Alaa Hassan
Assistant Professor of Public Health, Beni Suef University
Dr. Maha Mowafy
Assistant Professor of Family Medicine, Cairo University

\section{ADVISORY COMMITTEE (in alphabetical order)}

\author{
Dr. Hussein Aboul Makarem \\ Dr. Amr El-Ayat \\ Dr. Atef El-Shitany \\ Dr. Ashraf Fouad \\ Dr. Fatma El-Zaharaa Geel \\ Dr. Sofie Hanna \\ Prof. Ezzeldin Osman Hassan \\ Dr. Amal Philip
}




\section{List of Acronyms}

\begin{tabular}{|c|c|}
\hline ANC & antenatal care \\
\hline C-section & Caesarean section \\
\hline CAPMAS & Central Agency for Public Mobilization and Statistics \\
\hline $\mathrm{CCO}$ & Curative Care Organization \\
\hline CDA & Community Development Association \\
\hline CEOSS & Coptic Evangelical Organization for Social Services \\
\hline CFPA & Cairo Family Planning Association \\
\hline CME & continuing medical education \\
\hline COCs & Combined oral contraceptives \\
\hline CPR & Contraceptive prevalence rate \\
\hline CSI & clinical services improvement \\
\hline CSIA & Clinical Services Improvement Association \\
\hline ECP & emergency contraceptive pills \\
\hline EDHS & Egypt Demographic and Health Survey \\
\hline EFCS & Egyptian Fertility Care Society \\
\hline EFPA & Egyptian Family Planning Association \\
\hline EGP & Egyptian Pound ${ }^{1}$ \\
\hline EJMDA & Egyptian Junior Medical Doctors Association \\
\hline FGDs & focus group discussions \\
\hline $\mathrm{FGM} / \mathrm{C}$ & Female genital mutilation / cutting \\
\hline FHM & Family Health Model \\
\hline FHU & Family Health Unit \\
\hline FOF & Family of the Future \\
\hline FP & family planning \\
\hline GOE & Government of Egypt \\
\hline GOTHI & General Organization for Teaching Hospitals and Institutes \\
\hline GP & General Practitioner \\
\hline $\mathrm{HIO}$ & Health Insurance Organization \\
\hline HIV & human immunodeficiency virus \\
\hline HSRP & Health Sector Reform Program \\
\hline IEC & information, education and communication \\
\hline IDIs & in-depth Interviews \\
\hline IPPF & International Planned Parenthood Federation \\
\hline
\end{tabular}

${ }^{1} 1$ US $\$=8.83$ Egyptian Pounds 


$\begin{array}{ll}\text { IUD } & \text { intrauterine device } \\ \text { LAM } & \text { lactational amenorrhea method } \\ \text { MCH } & \text { maternal and child health } \\ \text { MIS } & \text { management information systems } \\ \text { MOF } & \text { Ministry of Finance } \\ \text { MOHP } & \text { Ministry of Health and Population } \\ \text { MOSS } & \text { Ministry of Social Solidarity } \\ \text { NGO } & \text { nongovernmental organization } \\ \text { NODCAR } & \text { National Organization for Drug Control and Research } \\ \text { NPC } & \text { National Population Council } \\ \text { Ob/Gyn } & \text { obstetrics and gynecology } \\ \text { OC } & \text { oral contraceptive } \\ \text { PHC } & \text { primary health care } \\ \text { PNC } & \text { postnatal care } \\ \text { PoPs } & \text { progestin only pills } \\ \text { PVO } & \text { private voluntary organization } \\ \text { RCT } & \text { Regional Center for Training } \\ \text { RH } & \text { reproductive health } \\ \text { SFD } & \text { Social Fund for Development } \\ \text { SHI } & \text { Social Health Insurance } \\ \text { SIS } & \text { State Information Service } \\ \text { SPA } & \text { service provision assessment } \\ \text { SRH } & \text { sexual and reproductive health } \\ \text { TFR } & \text { total fertility rate } \\ \text { TMA } & \text { total market approach } \\ \text { UNDP } & \text { United Nations Development Program } \\ \text { UNFPA } & \text { United Nations Population Fund } \\ \text { USAID } & \text { United States Agency for International Development } \\ \text { WTP } & \text { willingness to pay } \\ & \end{array}$




\section{Executive Summary}

\section{BACKGROUND}

The recent increase in Egypt's total fertility rate from 3.0 in 2008 to 3.5 in 2014, along with stalling contraceptive rates and persistent unmet need for family planning (FP), highlights a need to explore new venues for providing FP services. The specific objectives of this study are to determine the size, scope, and scale of private sector FP providers (private physicians, nongovernmental organization clinics, and private pharmacies); examine the policy and regulatory environment for private provision of FP products and services; assess business, financing, and training needs of the private health sector and the potential for expanding its role in FP service provision.

\section{METHODOLOGY}

The study involved: (1) a review of published and gray literature (2000-2015) on the role of the private sector in providing family planning services in Egypt and aspects of the policy environment that may influence the private sector; (2) secondary analysis of Egypt Demographic and Health Survey (EDHS) data and market segmentation analysis to identify socio-demographic and economic characteristics of women who could be targeted by the private sector; (3) in-depth interviews with 10 key informants from public and private sectors and development agencies; (4) in-depth interviews with 30 private sector providers; and (5) 10 focus group discussions with married women of reproductive age (18-40 years) who had ever used FP methods from the public or private sector. Study participants were recruited from Cairo, Assiut, and Gharbeya governorates. This study defines private sector as facilities that are directly involved in the provision of FP services and that are not affiliated with the government, namely private clinics, NGO clinics, and pharmacies. The role of pharmaceutical companies is briefly addressed, as they influence the performance of the private sector through manufacture or importation of contraceptives.

\section{KEY FINDINGS}

There has been a steady decline in private sector contribution to FP service delivery since 1995, when 64.3\% of FP users obtained their methods from the private sector. Today, $43 \%$ of current users obtain their contraceptives from the private sector (21.7\% from a private clinic/hospital, $20.5 \%$ from a pharmacy, and $0.6 \%$ from an NGO facility). Use of private clinics/hospitals is highest among women in the Frontier governorate (26.8\%), users of female sterilization $(78.7 \%)$, women with more than secondary education (39.4\%), and women in the highest wealth quintile (33.9\%). The largest percentage of pharmacy users was recorded among pill, condom, and one-month injectable users $(63.5 \%, 74.9 \%$, and $50.0 \%$, respectively), and those who live in the Frontier governorate and urban Lower Egypt (29.6\% and 27.2\%, respectively). Use of NGOs as a source of contraceptives is generally low $(0.6 \%)$, but tends to be higher among women who live in urban Lower Egypt (1.2\%) and those who are using an IUD (1.0\%).

Key challenges that hinder the private sector's contribution to FP service delivery are: (1) lengthy and complicated registration procedures, along with a rigid pricing system, which limit the range of family planning methods available on the market; (2) FP method stock-outs often due to lengthy importation procedures; (3) low demand for contraceptives; (4) inadequate knowledge about FP methods, among users and providers, particularly among private doctors; (5) poor counseling on FP by private providers, especially pharmacists; (6) staffing and funding constraints faced by NGOs that provide FP services; (7) high consultation fees charged by private physicians; (8) lack of a platform that brings private sector providers 
together; and (9) competition posed by the public sector, which provides relatively good services at a very low (subsidized) price and precludes the private sector from selling certain methods (e.g. Implanon).

Despite the above challenges, this study identifies several opportunities for an increased role for the private sector in family planning service delivery. Currently, more than 16 million women in Egypt (out of 22.5 million married women of reproductive age) have a demand for contraception (i.e. these women are either currently using contraception or wish to postpone their next pregnancy or to stop childbearing altogether but are not using contraception). ${ }^{2}$ Of those 16 million women, more than 2.8 million have an unmet need for FP, meaning that their stated demand is unsatisfied. The private sector could help fulfill some of this unmet need by specifically targeting women in the upper two wealth quintiles (approximately one million women) and those with secondary or higher education. Young men and women, including factory workers and university students, constitute another potential market for the private sector.

Owing to their on-going relationships and established rapport with their customers, private physicians and pharmacists are well positioned to address reasons for unmet need for family planning, such as infrequent sex, fear of method side-effects, and husband's disapproval. Antenatal (ANC), postnatal, and children's health care are predominantly provided by the private sector, and those visits should be capitalized on to provide FP services as well as counseling for husbands about FP.

At the policy level, amendments made by the Egyptian government to existing investment laws could make the Egyptian market more attractive to pharmaceutical companies. Also, Egypt's 2014 Constitution and the Sustainable Development and Population Strategies highlight the role of the private and NGO sectors in development and in strengthening Egypt's national population program. The Social Health Insurance law that is currently being drafted by the Ministry of Health and Population (MOHP) and the Reproductive Health Fellowship program that has recently been established by MOHP both offer opportunities for the private sector to play a greater role in family planning.

\section{RECOMMENDATIONS}

To improve current trends in contraceptive uptake and provide expanded service delivery and contraceptive options for Egyptian couples, we propose the following recommendations:

1. Adopt a total market approach whereby MOHP facilities target those who live in remote rural and low income urban areas; NGOs target lower middle-class women; private doctors target middle- and upper-class women; and pharmacists target all groups of women and possibly husbands.

2. Create demand for private FP services through social marketing campaigns that specifically target young couples, those in the upper two wealth quintiles, and those who live in urban areas. Innovative communication channels such as social media and mobile technology should be explored.

3. Capitalize on all opportunities to counsel women and their husbands about FP including during antenatal care, postnatal care, and children's health care visits.

4. Educate physicians and pharmacists about new family planning methods through brochures, newsletters, conferences, and medical representatives.

5. The private sector should make services more attractive to clients through enforcing service delivery standards, upgrading their FP knowledge and skills and offering extended hours and additional services.

\footnotetext{
${ }^{2}$ This estimate is based on EDHS 2014 data, which indicates that $70 \%$ of married women of reproductive age have demand for contraception (table 6.20) and that married women of reproductive age constitute $25 \%$ of Egypt's population of 90 million (US census Bureau 2004).
} 
6. Ensure method availability and expand method choice through simplifying registration and importation procedures and revisiting pricing policies for FP methods, and sponsoring more research to measure acceptability and typical use-effectiveness of new FP methods that could be introduced to the Egyptian market (e.g. Standard Days Method, Sino-implant, Sayana press, and the contraceptive vaginal ring).

7. Support the creation of more private sector outlets for clients through easing funding and registration procedures for NGOs, and MOHP increasing the availability of staff and subsidized FP methods for NGOs. Additionally, the RH Fellowship program offered by the MOHP to General Practitioners should be strengthened and scaled up to attract more physicians (more on this program is provided under section titled Who Provides FP Sservices in Egypt.

8. Create linkages among private sector providers through a branded network that links pharmacists and private doctors (e.g. Ask - Consult) could serve as a platform for reaching both groups of health care providers, strengthening their capacity, improving quality of services, and ensuring referral of clients between physicians and pharmacists and vice versa.

9. Integrate FP and contraceptive technology into medical and pharmacy school curricula: Training for medical and pharmacy students should include expanded information on FP while training for house officers and Ob/Gyn residents should include practical training in FP counseling, IUD and implants insertion and removal.

10. Foster public-private partnerships: MOHP should make all FP methods available to the private sector (including three-month injectables and subdermal implants) in return for provision of adequate statistics and good quality services. Pharmaceutical companies could provide training in all FP methods to physicians who are affiliated with MOHP (most of whom also have their own private practices), which would give the companies an opportunity to promote their products to the private sector as well as the public. 


\section{Background and Justification}

Since the inception of the National Population Program in the mid-1960s, Egypt has made significant strides in lowering fertility levels. Total fertility rate (TFR) decreased from 5.3 in 1980 to 3.0 in 2008, though it increased to 3.5 in 2014. Knowledge of FP methods is nearly universal, with $99.9 \%$ of married women of reproductive age knowing at least one FP method. Use of FP has also increased significantly, from $24 \%$ in 1980 to 59\% in 2014 (Ministry of Health and Population, El-Zanaty and Associates and ICF International, 2015). Despite these achievements, meeting the growing FP needs of Egyptian couples continues to be a key challenge facing the country. The recent increase in the TFR from 3.0 in 2008 to 3.5 in 2014, along with persistently high contraceptive discontinuation rates of 30\% in 2014, have raised the alarm that current FP programming in Egypt is not maintaining momentum and highlighted the need to reinvigorate it. The increase in the TFR has significant implications for population growth, which translates to greater strain on already limited resources. If the current annual population growth rate of $2.5 \%$ continues, Egypt's population will reach 120 million in 2030 (Ministry of Population, 2015). The continued unmet need for contraceptives $(12.6 \%)$ as well as the population momentum driven by the large cohorts of young people reaching reproductive age require an objective search for ways to meet the increasing FP needs in the future.

The public sector is the largest provider of FP services in Egypt, with more than half of FP users (57\%) obtaining their method at a public facility (Ministry of Health and Population, El-Zanaty and Associates and ICF International, 2015). Between 1977 and 2007, the Ministry of Health and Population (MOHP) received over $\$ 300$ million in USAID funds to support the refurbishment of health facilities, training of service providers, research, commodities supply, and information, education and communication (IEC) activities. However, after phasing out of USAID funding of FP activities within MOHP in 2011, the Government of Egypt (GOE) has become the main financer of the Egyptian FP program. Although the MOHP is the largest provider of FP services, it may not be able to meet the needs of the growing cohorts of women entering reproductive age, some of whom may not prefer or need the free public service. Thus, options to expand FP access through the private sector (for-profit and not-for-profit) should be explored.

The private sector is increasingly recognized as a vital partner in global efforts to provide FP services and commodities, and private sector providers can expand couple's access to FP services and products (Marek et al., 2005). The private sector is defined as all the providers, suppliers, and ancillary and support services that lie outside the public sector. These include commercial or for-profit entities, not-for-profit organizations, community groups, informal vendors, and a small but growing number of private providers, such as doctors, pharmacies, and hospital staff (Armand et al., 2007). Reviews of public and private sector service data from a number of countries demonstrate that while a substantial number of people in the highest income quintiles utilize subsidized government health services, many people in the lowest income quintiles still go to the private sector for their FP needs (Gwatkin et al., 2004; Marek et al., 2005).

An assessment of the involvement of the private sector in FP services delivery in Egypt in 1991 concluded that there was a widespread private network of diverse distributors and providers for service delivery, such as pharmacies, private physicians, and non-governmental facilities (Ravenholt, 1991). It pointed out that the willingness and ability of Egyptians to pay for FP services may have been underestimated. However, it also noted that government regulations seriously constrained the ability of the private sector to contribute fully to FP service delivery. The assessment concluded that there was potential, though constrained, for increased involvement of the private sector in the delivery of FP services in Egypt.

The social, political, and FP environment has changed over the past 25 years, contributing to the need for a new study. Also, the fact that modern contraceptive use has stalled, and even declined slightly between 2008 
and 2014 (from 57.6\% to 56.9\%), along with diminishing donor funding of the public sector suggests the need to explore new venues for providing FP services to meet the needs of various sub-groups of women who are in the reproductive age. Thus, it is important to explore private sector involvement in FP services delivery as a key approach to increase availability of and access to high quality FP services for all Egyptians seeking those services.

Through the Evidence Project and with funding support from USAID/Egypt, the Population Council/Egypt conducted a study of various components of the private sector that examines the policy environment, service provision, provider networks, pharmaceutical products and supply, as well as clients' needs, perceptions, and willingness to pay for FP services. 


\section{Study Objectives}

The overall goal of this study is to identify opportunities to increase access to family planning services for all women and couples and ultimately help more women prevent unplanned and mistimed pregnancies. The specific study objectives are to:

- Conduct an in-depth analysis of the current involvement of the private sector in the provision of FP services in Egypt;

- Identify specific areas for increased involvement of the private sector in the provision of FP services in Egypt; and

- Identify ways in which different stakeholders and the donor community can stimulate and facilitate increased involvement of the private sector in the provision of FP services in Egypt. 


\section{Conceptual Framework}

The role of the private sector in FP service delivery is determined by the interaction among several key players:

The private sector which is composed of private physicians, NGOs, pharmacists, non-medical providers (e.g. supermarkets), wholesale agents who either produce or import contraceptive commodities, and distributors.

The public sector which is composed of government facilities that provide subsidized FP services.

The client who seeks services at a public facility, private clinic, pharmacy, or NGO facility based on criteria such as cost, quality, convenience, or other factors.

An ecosystem which includes policies, regulations, socio-economic, cultural and political factors and which influences both supply of and demand for FP services, as well as utilization of private services.

\section{FIGURE 1 | CONCEPTUAL FRAMEWORK OF THE PRIVATE SECTOR IN FP SERVICE DELIVERY}

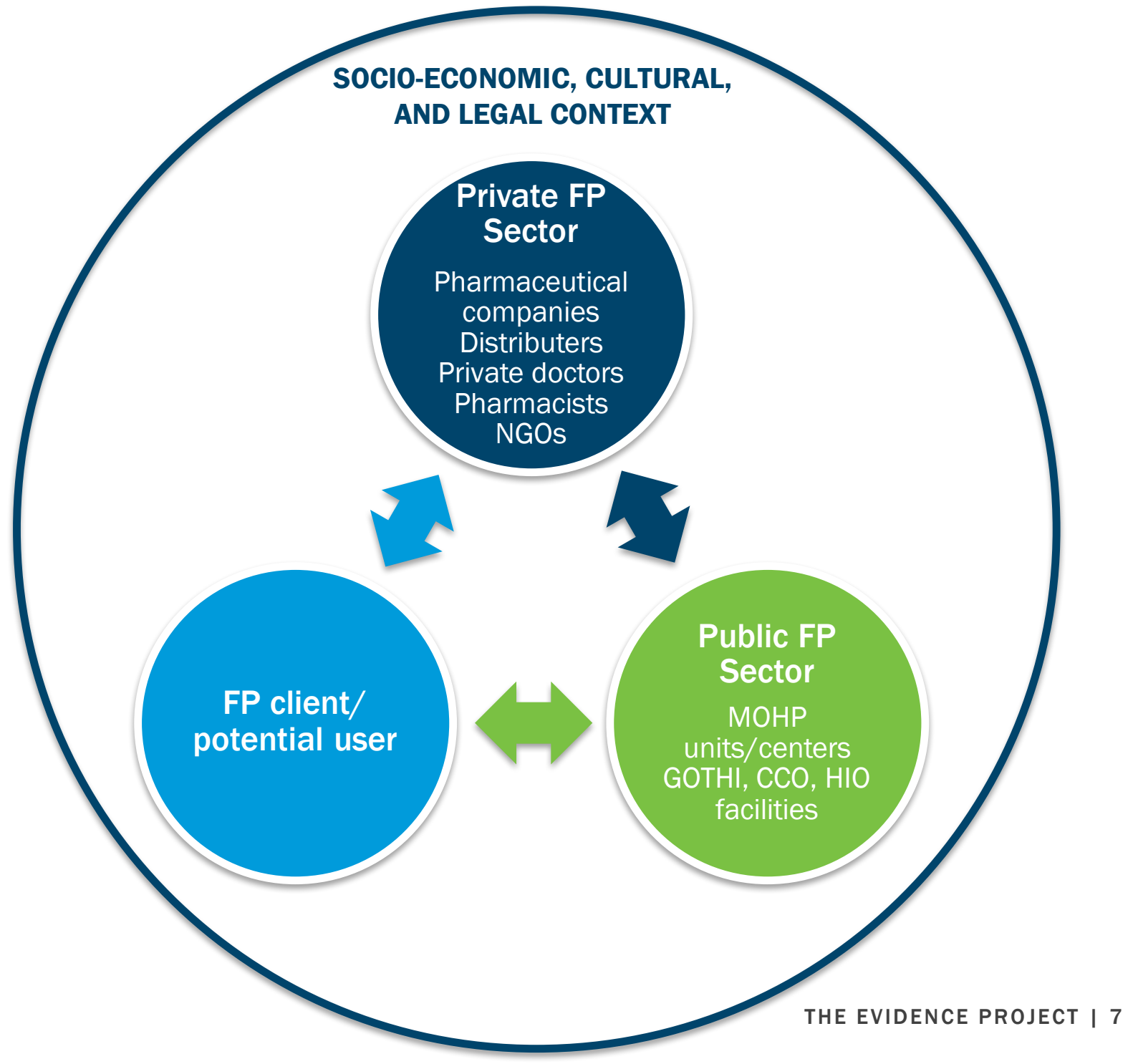




\section{Methodology}

For the purposes of this study the private sector is defined as individuals or organizations that provide FP services or commodities and that are not managed by the Egyptian government. This includes pharmaceutical companies, contraceptive distributors and importers, private clinics, pharmacies, and NGO clinics. The study methodology involved: (1) review of the published and gray literature produced between 2000 and 2015 on the role of the private sector in providing family planning services in Egypt, as well as government policies and donor-country strategies addressing the role of the private sector in FP service delivery; (2) secondary analysis of Egypt Demographic and Health Survey (EDHS) data and market segmentation analysis to identify socio-demographic and economic characteristics of current and potential FP users who could be targeted by the private sector; (3) in-depth interviews (IDIs) with 10 key informants from the public and private sectors, as well as development partners, to understand prevailing attitudes toward private sector engagement and to identify opportunities, challenges, and potential solutions for formalizing and strengthening the private sector involvement in FP services in Egypt; (4) in-depth interviews (IDIs) with 30 private sector providers to explore the regulatory environment for FP service provision in the private sector, contraceptive methods available to the private sector, challenges faced by the private sector in providing FP services, sources of information about contraception, and the private sector's FP training needs; and (5) 10 focus group discussions (FGDs) with married women of reproductive age (18-40 years) who had ever used FP methods (from the public or private sector), to understand their perception of FP services delivered by the private sector, willingness to pay for private services, and how private services can be improved and made more accessible to them. ${ }^{3}$

The study was conducted in the governorates of Cairo, Assiut, and Gharbeya. Cairo was selected because it is the capital city and has the largest proportion of private sector providers. Assiut and Gharbeya were selected to represent Upper and Lower Egypt, respectively. The CPR in Cairo, Assiut, and Gharbeya is 64\%, 41.4\% and $63.2 \%$, respectively. The study protocol and data collection instruments were reviewed and approved by the Population Council Institutional Review Board (protocol number 713) and MOHP Research Ethics Committee (protocol number 27-2015/14). Data were collected in October - November 2015. Characteristics of study participants are described in Appendix I.

\footnotetext{
${ }^{3}$ FGDs were not conducted with husbands because condom use is negligible in Egypt $(0.5 \%)$ and vasectomy is practically nonexistent (Ministry of Health and Population, El-Zanaty and Associates and ICF International, 2015).
} 


\section{Key Findings}

The study findings are divided into four sections. Section I provides an overview of the current sociodemographic situation in Egypt, as well as the economic and policy environment in the aftermath of the January 25 and June 30 Revolutions. This section also provides a brief history of Egypt's population program and previous initiatives that supported the FP private sector. Section II describes the health care system in Egypt, with a focus on key outlets that provide FP services. Section III examines characteristics of users of different FP outlets in Egypt and shows trends in private sector use between 1995 and 2014. Section IV discusses challenges hindering the growth of the FP private sector and opportunities for increased involvement. The final section of the report provides conclusions and policy recommendations for increased private sector involvement and better fulfilment of unmet FP needs.

\section{THE CONTEXT}

\section{Egypt's Socio-Demographic, Economic, and Policy Environment}

Egypt has a population of 90 million and an annual population growth rate of $2.5 \%$. A substantial proportion of Egypt's population is composed of young people, with 10-29 year olds constituting over $40 \%$ of the country's population (CAPMAS, 2011). On average, Egyptian women marry at age 20, while men marry at age 26. However, early marriage is still common for young women in some areas. According to the 2014 Survey of Young People, 21.1\% of married female youth ages 15-29 were married before age 18, with substantially higher percentages (33.3\%) recorded in rural Upper Egypt (Sieverding and Ragab, 2015).

Egypt has achieved remarkable gains in educational attainment, with almost universal school enrollment rates (Krafft, 2015), though married women (15-49) generally have lower levels of education: one-third have only some primary or no education, $17.4 \%$ have completed primary and some secondary, and over half (52.4\%) have secondary or higher education (Ministry of Health and Population, El-Zanaty and Associates and ICF International, 2015).

Until 2011, Egypt's economy was growing at a rate of 5\%-6\%, however political unrest following the January $25^{\text {th }}$ Revolution and subsequent political changes have taken their toll. The turbulent security situation and uncertainty about the country's economy resulted in plummeting tourism and foreign investments, and deterioration of the business climate (World Bank, 2015). Unemployment rates went up to $22.1 \%$ among young men 15-29 years old and to $42.4 \%$ among young women of the same age group (CAPMAS, 2016). Formal sector jobs have become scarce, so more young people (40\%) end up working in the informal sector, which offers low wages, irregular hours, and few or no benefits. Today, about one quarter $(26.3 \%)$ of Egypt's population lives below the national poverty line and nearly $40 \%$ lives in slum areas (including informal and unsafe areas), with limited or no access to basic services (UNDP and Ministry of Planning, Monitoring and Administrative Reform, 2015, UNICEF and ISDF, 2013).

\section{Egypt's Population Program: Historical Overview ${ }^{4}$}

Egypt has had one of the most successful family planning programs in the Arab region. Launched in 1966 when the TFR was nearly 7.1, the program went through several phases, starting with limited service delivery that focused on oral pills, then shifting focus to women's development (1975-1980), intensive FP service strengthening and demand creation (1985-2000), and finally an integrated FP/ RH model (2002-2010). The most intense period of the program was between 1985 and 2000, when program activities grew in size and

${ }^{4}$ This section is largely based on information obtained from Robinson and El-Zanaty, 2006 and USAID, 2011 
complexity with support from international donors, mainly USAID. During that period, the program focused on four main areas: advocacy and policy dialogue, increased access to and improved quality of services, generation of demand for FP through information, education, and communication activities (IEC), and research.

Early FP projects included training clinicians to deliver services; building the capacity of local training institutions; ensuring availability of contraceptive commodities; establishing a reliable logistics system; making contraceptives available to the commercial sector; and supporting local NGOs in providing high-quality services. Throughout the 1990s and 2000s, the focus was more on improving quality of public and private services.

Under the leadership of the Egyptian Fertility Care Society (EFCS), clinical trials and training were conducted for new contraceptive technologies such as three-month injectables, Norplant, and medically-indicated surgical contraception. Results of those studies, coupled with diligent advocacy efforts and policy dialogue, led to the introduction of three additional methods into the program [the Copper T intra- uterine device (IUD), three-month injectables, and Norplant) and, consequently, expanded method choice. The IUD and injectables were made available to both public and private sector providers.

FP programming was strong in Egypt between the late 1980s and the early 2000s, with the private sector playing a significant role through private pharmacies and private doctors (e.g. Ask - Consult initiative) and NGO initiatives like Family of the Future for social marketing of family planning methods and the Clinical Services Improvement (CSI) project, which offered high-quality services at an affordable cost. Those projects are described in more detail later in this section.

In 1994, MOHP with USAID support, launched a nationwide quality assurance program to improve the quality of services in public clinics. Under this program, the Ministry developed a checklist of 101 points by which quality of services could be measured and rated. Clinics were then evaluated using this list and those that scored 100 were given cash incentives and a "Gold Star," which was displayed at the clinic entrance. This program resulted in significant improvements in the quality of public services and led to increased service utilization.

This period also witnessed the establishment of training centers like the Regional Center for Training (RCT) in 1988, which delivered clinical FP \& RH training to physicians, nurses, pharmacists, and social workers.

Efforts aimed at improving service delivery and expanding method choice were coupled with intensive demand creation activities. Between 1985 and 1997, IEC Centers affiliated with the State Information Service (SIS) delivered media campaigns that informed the public about FP, the economic and health benefits of smaller families, and promoted specific FP methods and source of supply. The state-run TV station offered free airtime as a public service.

Concerted service strengthening and demand creation efforts, along with strong political support, resulted in a significant increase in CPR from 37.8\% in 1988 to 56.1 in 2000 and a decline in the total fertility rate from 4.4 to 3.5. It has been argued that making the IUD widely available in both public and private sectors was responsible for the remarkable increase in CPR from 38\% in 1988 to 47\% in 1992 (Robinson and El-Zanaty, 2006, p.89).

Following the 1994 International Conference on Population and Development (ICPD), emphasis shifted from providing a vertical FP program to an integrated model of RH and FP service delivery. Thus, MOHP shifted towards an integrated service delivery structure by expanding the family health model (FHM) in an effort to improve quality and facilitate access. The Health Sector Reform Program (HSRP) was initiated by 
MOHP in 1997 with support from USAID and other international donors. The primary focus of HSRP has been on improving health service delivery by primary health care centers / units using the FHM. . More description on the HSRP is provided below, in the section titled "Egypt's Health Care System."

For most of that time, USAID was the largest international donor to the Egyptian FP program. Between 1977 and 2006, USAID contributed more than $\$ 370$ million to improve quality and access to FP and reproductive health information and services. Among other things, funds covered the establishment of new facilities, renovation of existing facilities, training of health care providers, procurement of equipment and commodities, provision of information, education and communication (IEC) materials, and establishment of management information systems (MIS). Until 2004, USAID funded the delivery of IUDs and three-month injectables to the public sector (USAID, 2011).

In 2004, USAID and MOHP began working on a plan to enable MOHP to assume financial and technical responsibility for procuring and managing contraceptive supplies. In 2007, MOHP received its last supply of contraceptives from USAID and responsibility for the supply of contraceptives was turned over to the Government of Egypt (GOE) and private sources. Training of health care providers in contraceptive technology was integrated into more general training on maternal and child health (Robinson and El-Zanaty, 2006; USAID, 2011).

\section{Egypt's FP Program, 2006 - Present}

The FP program has been predominantly supported by the GOE since the phase out of USAID funding. The period 2005-2008 witnessed a slight increase in contraceptive prevalence rates from $59.2 \%$ to $60.3 \%$, along with a fertility decline from 3.1 to 3.0 (El-Zanaty and Way, 2009). However, the program has been negatively affected by political changes following the January $25^{\text {th }}$ Revolution, which was associated with disruptions of health services including FP, decreased resources, and decreased investment in training and supervision. Also, the increased strength of conservative groups after the Revolution and the rise of the Muslim Brotherhood to power was associated with disruptions of activities pertaining to family planning, women's empowerment, and abandonment of FGM/C. It is noteworthy that former President Mohamed Morsi (2012-2013) confirmed repeatedly that Egypt's large population was an added value that should be commended and encouraged and hence government commitment to FP diminished during that period.

The current government is committed to addressing Egypt's population problem. Article 41 of Egypt's 2014 Constitution reads: "the State is committed to implementing a population program that ensures a balance between population growth rates and available resources and the maximization of investment in human resources and enhancing population characteristics within the framework of sustainable development." President Sisi (2014-present) publicly declared that uncontrolled population growth is a threat to national security, and that the benefits of economic growth cannot be reaped unless the rate of population growth is slowed. In one of his speeches, he was even more explicit in asking couples to space births and to stop at three children, and asked the Grand Sheikh of Al-Azhar if this was haram (forbidden by Islam) or halal (sanctioned by Islam). The Grand Sheikh replied by saying that it was "halal, halal, halal!"

Moreover, Egypt's Population Strategy 2015-2030 states that the government is responsible for informing society about risks associated with high fertility, and for providing high-quality services for those who need them, as well as free services for low-income families. Thus, FP services are provided at nominal fees in a wide network of public facilities (see the next section for more detail).

In March 2015, a special Ministry for Population was established to coordinate population activities with other ministries. However, that Ministry was dissolved in September of the same year and its activities were merged into those of the Ministry of Health, and a Deputy Minister was assigned to oversee implementation 
of population-related activities. However, the National Population Council (NPC) retains responsibility for formulating national population policies and for sponsoring the population and FP research necessary for policy development.

Since the phase out of USAID funds, the GOE has been the main financer of FP services. MOHP receives EGP 100-120 million every year from the Ministry of Finance for contraceptive procurement. FP methods are heavily subsidized by the Egyptian government, as shown in Annex II. For some FP methods (e.g. Implanon and three-month injectables), the purchase price for MOHP is more than eight times the selling price at public facilities.

Despite the availability of funds to support contraceptive procurement, piecemeal financing of contraceptives remains an issue undermining contraceptive security in MOHP facilities. Although additional requests for commodity funding are usually fulfilled later in the fiscal year, those funds are often received too late to be spent before the end of the fiscal year, often resulting in contraceptive stock-outs (Ahmed et al., 2010). Moreover, service provider training and supervision activities were negatively affected by the discontinuation of USAID funding, which used to cover training and travel costs (Health Systems 20/20 Project, 2012).

The FP program currently receives support from UNFPA to expand contraceptive choice through pilot testing the introduction of emergency contraceptive pills (ECP) into public facilities, and to integrate FP into postpartum and postabortion care. UNFPA is also supporting a few media activities to promote the two-child family norm.

Today, $58.5 \%$ of married women use contraception and have, on average, 3.5 children during their reproductive life. The most widely-used FP methods by currently married women are the IUD, oral pills, and injectables (used by $30.1 \%, 16 \%$, and $8.5 \%$ of currently married women, respectively). On the other hand, one in every three FP users discontinues or switches FP methods within 12 months of use, and 12.6\% of married women say they would like to postpone or stop childbearing but are not using contraception (Ministry of Health and Population, El-Zanaty and Associates and ICF International, 2015).

\section{Previous Programs Involving Private Family Planning Sector}

In 1977, USAID/Egypt began providing assistance to the Government of Egypt in the area of population and health. From then until September 30, 2005, USAID/Egypt obligated approximately \$one billion for its health and population activities. Family planning and reproductive health accounted for $\$ 374$ million, or about 42 percent, of the \$one billion obligated. Beginning in 2005, USAID phased out its support for contraceptives, with the last deliveries made in 2007.

Most of the international FP funding to Egypt over the last 30 years focused on strengthening the public sector. In addition, several USAID-funded projects supported the private sector, namely Family of the Future, Ask-Consult, The Doctor, and Clinical Services Improvement Projects (CSI). Other international organizations such as UNFPA and IPPF have supported EFPA to establish "youth friendly clinics," which offer family planning, among other services, to young people. This section will focus on those initiatives that had family planning as a primary focus. Documentation describing these projects and their outcomes is, unfortunately, limited.

\section{Family of the Future (1981 - 1990)}

This social marketing program aimed to involve private sector medical care providers in FP service delivery. Family of the Future (FOF) was a semi-private, not-for-profit FP organization that was initially an affiliate of the Egyptian Family Planning Association (EFPA). They obtained free FP methods from USAID and sold 
them to private sector providers at subsidized prices. FOF mainly distributed oral pills (Norminest), Copper T IUD, vaginal foaming tablets (Amaan), and condoms (Golden Tops) in both urban and rural areas. FOF advertised its products through medical representatives, as well as extensive use of brand-specific media campaigns. The organization was dissolved in 1990, following internal financial and legal disputes (Robinson and El-Zanaty, 2006, pp. 86-87).

\section{Ask-Consult Network (1994-2008)}

In 1994, Pathfinder, with USAID funding under the POP III project, developed the Ask-Consult Network to expand the role of physicians and pharmacists in delivering FP services. The Project trained pharmacists to provide basic counseling to their customers about FP and refer them to trained physicians who were affiliated with the network, which mostly operated in urban areas. Anecdotal reports suggest that the project was successful in building the capacity of physicians and pharmacists to provide FP services and in increasing numbers of FP acceptors. The Ask-Consult Network continued to receive support from USAID through the POP IV, TAHSEEN, and Communications for Healthy Living (CHL) projects. In 2003, Ask-Consult expanded its scope to include counseling and referral for maternal, child, and family health services. In 2008, Ask-Consult Corporation was established as a not- for-profit entity that provides training to physicians and pharmacists, but the network's activities stopped in 2011 due to lack of funds. The Ask-Consult Network database currently has more than 30,000 pharmacists (Ask-Consult Corp. Director, personal communication).

\section{The Doctor's Project}

The Doctor's Project, implemented in the early 1990s, was funded by USAID and administered by the Egyptian Junior Medical Doctors Association (EJMDA) under the supervision of the Ministry of Social Affairs. The Doctor's Project mobilized private practice physicians to deliver quality family planning services by providing them with funds to set up their own private practice and providing them with the necessary training and equipment. To our knowledge, no evaluation was conducted to measure the project impact or outcomes.

\section{Clinical Services Improvement Project (CSI)}

The CSI Project was launched in 1988 as a spin- off of the Egyptian Family Planning Association. CSI's goal was to establish new and upgrade existing physical facilities and equipment, create effective management systems, and develop effective community outreach systems (Robinson and El-Zanaty, 2006, p.89). The project received funds from USAID until 2003, after which USAID funding was phased out. The project had over 90 clinics distributed over governorate and district capital cities in 20 governorates in Upper and Lower Egypt. CSI clinics charged moderate fees for their services and largely catered to middle-class women. Although CSI service statistics revealed a high caseload and client reports suggested that CSI delivered high quality services, the project was unable to sustain itself after USAID funding stopped. In 2003, the Clinical Services Improvement Association (CSIA) was established. Today, CSIA has a total of 22 clinics located in five governorates, and is facing serious challenges securing doctors and FP methods at a subsidized price.

\section{Bank loans to assist the private sector}

In partnership with the Ministry of International Cooperation, USAID funded a credit guarantee program of EGP 33.9 million to guarantee bank loans and encourage private investment, including in the private health sector. Between 1991 and 2008, the program provided about 20,000 loans through the Credit Guarantee Corporation, supporting the establishment of pharmacies, private clinics, labs, medical centers, and other health businesses of which some provided FP services (USAID, 2011). 


\section{EGYPT'S HEALTH CARE SYSTEM}

\section{Current Structure and Future Directions}

Egypt's health care system is composed of several public and private entities. Among public providers are the Ministry of Health and Population (MOHP), the Health Insurance Organization (HIO), the General Organization for Teaching Hospitals and Institutes (GOTHI), the Curative Care Organization (CCO), and a number of other ministries (e.g. Ministry of Higher Education, which oversees university hospitals). Private health services are offered at private clinics and hospitals, NGO clinics, and pharmacies. MOHP is responsible for setting the policy and regulatory framework for health care in Egypt. HIO is Egypt's primary insurance provider and provides health insurance coverage to government employees, private sector employees who are formally employed, retirees, schoolchildren, and newborns. In addition, a number of private companies provide insurance to employees who are working for large private sector companies or multi-national organizations. Provision of FP services is described in the Section titled Who provides FP Services in Egypt.

In $2008-2009,57 \%$ of the population was insured by HIO. It is noteworthy that fewer women than men are covered by health insurance, as they are less likely to be formally employed. Also, household out-of-pocket payments makes up the largest share of health spending in Egypt (72\%) (Nakhimovsky et al., 2011). In general, Egyptian women tend to rely on the private sector for curative care services, but they rely on the public sector for FP services (Cairo Demographic Center, 2002).

As part of a major health sector reform program (HSRP) launched in 1997, MOHP has undertaken a series of steps to transform and strengthen the financing and delivery of health care services. Some of these changes include moving from independent, vertical programs to an integrated Family Health Model (FHM), changing the manner in which services are contracted and paid for, and making the social insurance system more sustainable (Health Systems 20/20 project, 2012). One of the overarching objectives of the HSRP was to help develop a sound and integrated health care system that is capable of regulating market-oriented services (Nakhimovsky et al., 2011).

The key principles of HSRP are: (1) to achieve universal health insurance coverage through a National Health Insurance Fund; (2) separate organizations that provide services from those that pay for care; (3) ensure that a basic benefits package of high-quality services is available to all Egyptians (USAID, 2011). The HSRP involves a shift to a single national, fee-based insurance reimbursable system for financing health services provided by both the public and private sectors. The expectation is that as the Egyptian economy grows, more clients will take formal jobs and hence will be insured through their employer or will be able to pay out of pocket.

As part of HSRP, an accreditation system was developed to assess and upgrade clinics. Those which met standards of quality were accredited as FHM clinics. Today, there are more than 1,500 accredited primary health care centers (USAID, 2011).

The Social Health Insurance (SHI) law that was recently drafted by MOHP seeks to ensure equitable access to adequate health services to all Egyptians. Based on that law, curative health care services will be provided by accredited health care providers who are contracted by MOHP. SHI will cover curative and rehabilitation services, while the Government will continue to provide a basic benefits package of services to all clients, regardless of their ability to pay (Robinson and El-Zanaty, 2006). The package will include preventive health services such as immunization, ANC and FP services.

All those with the ability to pay will directly contribute to the SHI - through payroll taxes for those who are employed by the formal sector, and contributions from the non-poor who are self-employed. HIO will serve 
as purchaser of health services, rather than provider. The SHI will contract with public and private providers, with clear rules and prerequisites on standards and quality, and with robust and independent mechanisms of accreditation. The program will be piloted in 2017 in the Suez Canal region and Sinai and then rolled out to other governorates over a five-year period.

\section{Regulations Governing the FP Private Sector}

\section{Manufacturers / importers of FP commodities}

The rules and regulations governing the establishment of a company to manufacture family planning commodities are the same as those governing the establishment of any medical supplies or pharmaceutical company. First, a manufacturer has to obtain licenses from the Ministry of Trade and Industry and the Ministry of Investment. Then, the manufacturer must register the product with the registration committee in the pharmaceutical sector of the Ministry of Health and Population (MOHP). ${ }^{5}$

Following the licensing of a pharmaceutical product, the next step is pricing, which is set by a committee affiliated with the MOHP. The Committee sets "fair" prices for products according to whether the product is generic or patented. 6 The price of a generic product should not exceed $65 \%$ of the original patented product available in Egypt, while the price for patented products should be 10\% less than the lowest price worldwide.

The public sector is both a significant competitor of private sector providers and an important customer of importing / distributing companies. For certain products, including contraceptives and vaccines, MOHP acts as an important consumer demanding large amounts of these products. However, for other FP commodities (e.g. subdermal implants and three-month injectables) the MOHP is the sole buyer and distributor, selling these commodities at MOHP facilities at a subsidized price. In other words, no other provider is allowed to buy Depo-Provera or Implanon from the manufacturing company or dispense those two products. NGOs can only dispense Depo-Provera if they obtain permission from MOHP (see the next section for more detail).

Registration for new hormonal products (such as oral contraceptives) and medical devices such as (such as IUD or subdermal implants) is required by the Central Administration for Pharmaceutical Affairs (CAPA) that is affiliated with MOHP and which serves as the regulating body within the Egyptian Drug Authority EDA. CAPA also provides importing license and approval for every pharmaceutical shipment. For quality assurance, CAPA performs routine inspection of imported shipments and sends samples to be analyzed at the National Organization for Drug Control and Research (NODCAR). The latter performs physical, microbiological, chemical, and sterility testing against the international reference standards for every product as well as standards for content and packaging set by the Ministry of Trade and Industry. In addition, the manufacturing or importing company has to pay taxes, even if the FP commodity is on the Essential Drug list (Ahmed et al., 2010).

The distribution of contraceptive commodities is based on monthly consumption reports received from service delivery points. The Egyptian Pharmaceutical Trading Company (EPTC) is one of the largest distributors of FP products to pharmacies. The company stores, and sells contraceptives and manages the contraceptive inventory and information systems for the public sector. In addition, it provides combined oral contraceptives (COCs) to private pharmacies and NGOs.

\footnotetext{
5 Ministerial decree no. 425 (2015)
}

${ }^{6}$ Ministerial decree no. 499 (2012) 


\section{Private physicians / NGO clinics}

To be allowed to provide services as a private physician in Egypt requires registering the private clinic at the Egyptian Medical Syndicate (the national association of medical doctors), followed by registration and licensure by the Independent Health Care sector of the MOHP.7 Registration papers include proof of the applicant's academic degrees and a copy of the contract for the space where the clinic will be set up. In addition, the space for the private practice must meet minimum hygiene standards set by the MOHP (e.g. good ventilation, availability of running water, sewage and waste disposal).

The procedures and regulations required for registration of a general practitioner (GP) clinic are the same as an $\mathrm{Ob} / \mathrm{Gyn}$ private clinic. A GP is allowed to conduct physical exam and prescribe medications but s/he is not allowed to perform minor procedures whereas an $\mathrm{Ob} / \mathrm{Gyn}$ is allowed to perform minor procedures such as cervical cautery, Pap smear, and removal of Bartholin cysts. Until the mid-1980s, the Egyptian Medical Syndicate held that only Ob/Gyn specialists working in hospitals or large clinics could insert IUDs (Robinson and El-Zanaty, 2006). Following strong pressure from the government, IUD insertion was allowed in public and NGO clinics, but permission for private clinics remained vague. It was not until 2010 that a ministerial decree was issued by former Minister Hatem El-Gabaly allowing trained GPs to insert IUDs in their private practice.

NGOs follow the same procedures as private doctors to register and establish a clinic, provided that provision of health care services falls within their mandate. NGO clinics that provide FP services are licensed and registered as "polyclinics." In addition, an NGO must be licensed by the Ministry of Social Solidarity (MOSS). Finally, for an NGO to receive funds from a local or international donor, they need to receive clearance from MOSS and the security authorities. ${ }^{8}$

Staff affiliated with the Independent Care sector of MOHP are required to conduct annual inspection visits to private clinics to ensure that they are following appropriate practices. However, due to staff shortages, they only act in the case of inadequate care or malpractice. Depending on the extent of the problem, health officials at the health directorate where the clinic is located could authorize closure of that clinic. ${ }^{9}$ NGO clinics report administratively and financially to MOSS and technically to MOHP.

\section{Pharmacists}

Private pharmacies play an important role as providers of family planning methods, especially those that do not require skilled care (e.g. pills, injectables, and condoms). ${ }^{10}$ Pharmacies are allowed to sell but not insert IUDs. Private pharmacies follow the regulations of the pharmaceutical sector of MOHP. To open a pharmacy, a pharmacist needs to be registered at both MOHP and at the Egyptian Pharmacists' Syndicate. A pharmacy must be managed by a pharmacist with a minimum of one year of pharmaceutical experience at a governmental or a nongovernmental facility. ${ }^{11}$ By law, the minimum distance between two pharmacies in a given area should be no less than 100 meters (with no maximum distance). Pharmacies are supervised by the pharmaceutical sector at MOHP, which ensures that available drugs have current expiration dates and are officially registered. A licensed private pharmacy is entitled to dispense all registered brands of family

\footnotetext{
7 Article 6 of Law for Medical Establishments number 51 (1981)

${ }^{8}$ Law for non-governmental organizations number 84 for 2002. For an NGO to receive funds, the application needs to be reviewed at MOSS, which in turn sends it to the security authorities for clearance.

9 Amendment \#153 for regulation of medical establishments (2004). Health facilities are supervised by staff in health directorates, who in turn report to central MOHP.

10 "Private pharmacies" in this report refers to community pharmacies and do not include hospital pharmacies, which only cater to the needs of inpatients.

11 Law \# 127 for pharmaceutical practice (1955).
} 
planning methods except for those that are disbursed only in MOHP clinics (e.g. Depo-Provera three-month injectables, and Implanon subdermal implants).

Private pharmacies receive contraceptives through distributor companies such as the Egyptian Pharmaceutical Trading Company (EPTC), which is a parastatal company, and other private distributers such as Sofico, Almotahida, Multipharma and Ibn Sina, as well as larger pharmacies. Pharmacies mainly obtain COCs and, to a lesser extent, injectables from EPTC. On the other hand, they are more likely to receive IUDs through commercial distributors. An earlier study of the role of the private sector in FP service delivery pointed out that pharmacies are required to pay cash for their contraceptive products, while they can purchase other pharmaceutical products (e.g. antibiotics) on credit (i.e. they pay after the product is sold) (Cairo Demographic Center, 2002). Since the price of contraceptives is set by the government, pharmacists do not have much leeway in setting the price they charge the customer. The margin of profit on family planning methods ranges between 5-10\% (compared to $20-40 \%$ for other products), but can be higher on contraceptives that are not officially registered or priced in Egypt (i.e. those imported informally). ${ }^{12}$ Profit margins are often increased through "bonuses" provided by distributors, who provide free packages of contraceptives if the pharmacy asks for a larger quantity or if the expiration date is close. Demand for IUDs is not high at pharmacies, as private doctors provide them at their clinics, thus pharmacists do not keep large stocks of IUDs. Two pharmacists in Cairo mentioned that, on average, they sell one IUD per month. There is higher demand for oral pills and, to a lesser extent, condoms.

\section{Who Provides FP Services in Egypt?}

Family planning services are provided through a wide network of governmental and nongovernmental / private facilities. Governmental facilities are mostly run by the MOHP and include primary health care facilities and hospitals, while non-governmental facilities include for-profit and not-for-profit organizations. For-profit providers include private doctors, private pharmacies, and private hospitals. Not-for-profit organizations include nongovernmental organizations that provide health services, including private voluntary organizations (PVOs), community development associations (CDAs), and clinics affiliated with mosques or churches. In theory, all of the private sector venues described below provide family planning services; however in reality the main private sector providers of family planning services are private physicians, pharmacists, and private voluntary organizations.

Pharmaceutical companies either manufacture or import contraceptives that are offered on the Egyptian market, and do not directly provide family planning services to clients. There are five key providers that manufacture and/or import family planning methods in Egypt: CID (a parastatal Egyptian company), DKT, MSD, Organon, and Pfizer. In addition, there are distributing companies that disburse FP commodities to family planning outlets (mainly pharmacies). The largest distributing company is the parastatal EPTC. A brief description of various sectors that directly provide FP services to clients follows below.

\section{Governmental facilities}

Egypt has nearly 6,000 governmental facilities that provide family planning services, of which approximately 5,000 are affiliated with the Population and FP sector at MOHP (National Population Council, 2015). Other governmental facilities that provide FP services are affiliated with the General Organization for Teaching Hospitals and Institutes (GOTHI), Health Insurance Organization (HIO), Curative Care Organization (CCO) and University hospitals. The MOHP family planning clinics include rural health units, urban health centers,

\footnotetext{
12 Some types of IUDs and three-month injectables are imported informally by private pharmacies, without going through a registered pharmaceutical company.
} 
Family Health Units, clinics at general service hospitals (i.e. general, district, and integrated hospitals) and mobile units.

MOHP facilities offer FP services from 8 am to 2 pm six days a week. In the evening the doctor who works at the health unit is allowed to use the unit as a private clinic and to charge fees. In rural areas, the same health unit provides family planning services, maternal and child health $(\mathrm{MCH})$ services, immunization services, and health registration services. The Health Sector Reform Program (HSRP), introduced in 1997, aimed at consolidating the above programs under one system, the Family Health Model. However, due to noticeable decreases in family planning utilization in clinics that adopted that model, family planning services were excluded from the HSRP (El-Zanaty and Associates, Ministry of Health and Population and UNFPA, 2011; Health Systems 20/20 Project, 2012).

At a minimum, MOHP family planning facilities are staffed by a physician, a nurse, and a Raeda Rifya (outreach worker), with the physician and the nurse offering both family planning and MCH services. Urban health facilities have more than one physician and nurse and responsibilities are segregated between FP and $\mathrm{MCH}$ staff. It is noteworthy that physicians and nurses who offer FP services report to the Population and Family Planning Sector of MOHP, while those who provide MCH services report to Primary Health Care Sector. Physicians who serve in MOHP health facilities are mostly recent graduates of medical school who are serving two years of mandatory public sector service before they start their clinical residency. Some remote areas of rural Upper Egypt have a shortage of physicians, especially female physicians, so one physician may serve more than one facility, spending one or two days at each facility.

Since the end of USAID funding in 2006/2007, GOE has been the main funder of contraceptive commodities, with a total budget of over EGP 100-120 million per year (equivalent to $\$ 12.5$ million). The following family planning methods are offered at MOHP facilities: COCs, progestin only pills (POPs), threemonth injectables, Copper T IUDs, and condoms. Some facilities carry one-month injectables, while subdermal implants are offered in selected urban facilities. COCs are locally manufactured by CID. MSD provides Implanon and Pfizer provides three-month injectables. IUDs and condoms are imported by companies like DKT or ACDIMA. To provide contraceptives to MOHP, companies have to go through a bidding process and to offer the lowest price.

To receive family planning services at an MOHP facility, a woman is not supposed to pay consultation fees, but she does pay a nominal price for the method; private and NGO facilities charge a higher price for FP services as they charge higher consultation fees. ${ }^{13}$ Annex III compares the prices of FP methods from MOHP, private, and NGO facilities. Mobile units, which provide FP and MCH services to women in remote and under-served communities, offer family planning methods free of charge. Facilities affiliated with teaching or university hospitals or HIO receive subsidized FP commodities from MOHP, but they charge slightly higher consultation fees. For example, an IUD (including insertion fees) costs EGP 11 at a teaching hospital FP clinic compared to two EGP at an MOHP facility. It is noteworthy that health insurance schemes in Egypt do not cover FP services. According to one of our key informants, "private insurance companies consider family planning a luxury and hence do not pay for it."

In terms of physical access, the availability of FP services, as part of public primary health care (PHC), is now almost universal, with 95 percent of the population living within five kilometers of PHC centers. Today, most FP clinics have the equipment and supplies needed to offer method choice and FP information. Most clients report that staff in public sector clinics treat them well. However, shortfalls in some aspects of quality of care still remain, such as limited physical and auditory privacy for counseling, deficiencies in privacy for patient

13 Although clients who receive services at public facilities are not supposed to pay consultation fees, one study showed that $30 \%$ of clients paid at least EGP 1.0 (Health Systems 20/20 project, 2012). 
examinations in some clinics, a lack of female physicians in almost half of clinics, and high physician turnover (Rabie et al., 2013). In an earlier assessment of HSRP clinics in six governorates, 25 percent of providers reported occasional method stock-outs. Methods more likely to be unavailable were Implanon, Levenor (progestin only pills), Microcept (COC) and Depo-Provera (Health Systems 20/20 project, 2012).14

Women who participated in the FGDs for this study (the majority of whom do not have paid jobs) appreciated the low cost of services offered through the public sector, the proximity of services, and convenient hours. However, some complained about poor treatment by nurses at public facilities who sometimes "yell at women." Women who participated in the study of HSRP clinics mentioned above reported high levels of satisfaction with services, specifically with providers listening to their questions and concerns, length of visits, and personal treatment by physician. Several clients across governorates mentioned increased availability of FP methods as a recommendation (Health Systems 20/20 project, 2012).

In an effort to improve the technical competence of physicians who work in family planning clinics and to reduce turnover, MOHP has recently started a Reproductive Health and Family Planning fellowship program which is a three-year program that involves both theoretical and practical training. The fellowship program is open to both MOHP and non-MOHP physicians. Graduates of this program will have better career opportunities within MOHP. They will also be allowed to open their own private practice under the title of Reproductive Health Specialists where they can provide basic RH services such as FP, ANC, PNC, and treatment of reproductive tract infections. So far, one cohort of approximately 20 Fellows (predominantly women) have completed the program and the second cohort is currently in its second year.

\section{Private clinics}

According to statistics from the Central Agency for Public Mobilization and Statistics (CAPMAS, 2014), there are more than 30,000 private clinics in Egypt. Private clinics tend to be concentrated in urban areas and large villages (28,314 clinics in urban areas and 2,440 in rural areas). GOE/ Health System policies allow physicians who work in public facilities to work in the private sector after work hours. Thus, nearly three quarters (74 percent) of doctors who work in the private sector have another government job, either at MOHP or a university (Cairo Demographic Center 2002). Private physicians who provide family planning services include General Practitioners (GPs), Ob/Gyn specialists, and consultants. Young doctors may find it difficult to establish their own clinics due to high costs, so some join polyclinics that include more than one specialty (e.g. OB/Gyn care, pediatric care, dermatology, and so forth) with special hours for each doctor.

In general, there are more male than female $\mathrm{Ob} / \mathrm{Gyn}$ specialists, hence private clinics that are run by female $\mathrm{Ob} /$ Gyn specialists tend to have a high client load. Ob/Gyn specialists offer gynecological services and delivery services in addition to FP services, while GPs, especially in poor or semi-urban areas, offer gynecologic, obstetric, and pediatric care in addition to internal medicine services for men and women. As the majority of doctors who work in private clinics have a government job, private clinics usually operate in the afternoon and evening, although more than one-third offer services in both the morning and afternoon or evening (Cairo Demographic Center, 2002).

Private clinics are more concentrated in urban areas, especially Cairo and other large urban centers (Nakhimovsky, 2011). On average, each private clinic serves a population of 673 persons, ranging from a low of 322 persons per clinic in urban Lower Egypt to a high of 9,605 persons in rural Upper Egypt. The distribution of private practices according to specialty varies widely across regions, with GPs forming a sizeable proportion of specialties in rural Upper and Lower Egypt (43 percent and 31 percent, respectively). Moreover, rural and urban Upper Egypt have higher percentages of Ob/Gyn specialists (23 percent and 17

\footnotetext{
${ }^{14}$ Six governorates where the study was conducted were Alexandria, Beni Suef, Dakahliya, Qaliobiya, Qena and Red Sea.
} 
percent) than other regions (15 percent) (Cairo Demographic Center, 2002). According to the same study, the percentage of female physicians is highest in Upper Egypt (34 percent), as compared to Lower Egypt (25 percent) and urban governorates (18 percent). On average female physicians constitute 38 percent of all $\mathrm{Ob} / \mathrm{Gyn}$ specialists, with a higher percentage of female Ob/Gyn recorded in Lower Egypt (43 percent).

All private physicians interviewed for this study reported that they offered family planning counseling to their clients. If a woman chose an IUD they inserted it for her, but if she chose another method (e.g. pills or an injectable) they advised her to buy it at the pharmacy. Some physicians reported obtaining IUDs and injectables from distributing companies directly (bypassing pharmacists) and charging their clients for the full package of services (e.g. IUD commodity, examination, and insertion). Moreover, there are anecdotal reports of physicians who buy IUDs, injectables, or implants at government facilities (at a subsidized price) and sell them at their clinics at a higher price. The cost of family planning services offered by private physicians varies widely depending on the physician's level of seniority, academic degrees, and neighborhood where the clinic is located. According to results of the FGDs with women and IDIs with private physicians and stakeholders, the cost of IUD insertion at a private clinic ranges from EGP 30-100 (US\$ 3.75-12.50) in poor neighborhoods to EGP 150-200 (US\$18.75-25.00) in middle-income neighborhoods and 300-350 (US\$37.5043.75) in high-income neighborhoods. A stakeholder from the pharmaceutical industry said, "The same physician would have two clinics one in Mohandessin and one in Hawamdeya ... in the former he would insert an IUD for EGP 300 while in Hawamdeya he would charge EGP 50.”

Private physicians rarely receive training in family planning unless they have a government job (i.e. working at MOHP, or a teaching or university hospital) through which they receive such training. Those who are affiliated with the MOHP mentioned that the Ministry provided training in the past but that those workshops have not been held in the last five years. A few private physicians who participated in this study mentioned that they received training in the past through Ask-Consult or The Doctor projects.

FP ever users who participated in FGDs believe private physicians are more competent in IUD insertion and that their clinics were cleaner and offered more privacy than public clinics. However, some women from rural areas and poor urban areas said that the difference between the two service options is not great enough to justify the high fees of private doctors.

Very little is known about the quality of care offered at private clinics. The above-mentioned study by the Cairo Demographic Center (2002) revealed a lack of infection control equipment in approximately one-third of private clinics that provide treatment services for sexually transmitted infections. Other aspects of quality, such as availability of FP methods, client-provider communication, and use of IEC materials, were not examined.

\section{NGO clinics}

In total, there are nearly $2000 \mathrm{NGOs}$ that provide family planning services in Egypt. However, according to NPC statistics, only 274 NGOs reported on their FP activities, which may suggest that some of the remaining NGOs have stopped their FP activities or have closed down altogether (NPC, 2015). The main NGO providers of FP services are the Egyptian Family Planning Association (EFPA), the Cairo Family Planning Association (CFPA), the Clinical Services Improvement Association (CSIA), the Coptic Evangelical Organization for Social Services (CEOSS), and the Coptic Organization for Social Services. In addition, there are clinics that are affiliated with mosques, churches, or community development associations (CDA) that offer family planning services within maternal and child health services $(\mathrm{MCH})$. Those clinics do not sell family planning methods, but direct the client to buy them at the pharmacy. 
EFPA, an affiliate of the International Planned Parenthood Federation (IPPF), has a total of 100 clinics distributed over 20 governorates and which EFPA directly manages. Additionally, EFPA supports 47 clinics that are managed by CDAs. This support involves provision of FP methods, technical training and monitoring of service providers. CFPA has a total of three clinics which they directly manage, while CSIA has a total of 22 clinics distributed over five governorates. Both CFPA and CSIA are spin-offs of EFPA. CSIA began in 1988 as a USAID-funded project (Clinical Services Improvement Project), but registered as a local NGO in 2005 after USAID funding ended.

In general, large NGO clinics that provide FP services are located in urban areas, while those run by CDAs are usually located in rural or slum areas. The majority of NGOs that provide FP services are located in Upper Egypt (36 percent), followed by Lower Egypt (32 percent), Urban Governorates (28 percent) and finally Frontier governorates (4 percent). The number of NGOs that provide FP services declined steadily between 1995 and 2015. A review of NPC statistics showed that the total number of NGOs that provided FP services went down from 669 in 1995 to 419 in 2014. An earlier assessment of NGOs that provide FP services showed most clinics comprised one examination room, a waiting area, and a toilet. In 2002, most NGO clinics (90 percent) had female doctors, 20 percent had no nurse, and 81 percent had no Raeda Rifya.

NGO clinics cater to the needs of lower-middle-class women who cannot afford the private sector but who do not need the free service offered at public facilities. They also serve women in communities that have no public services (e.g. slum areas). Technical supervision of NGO clinics (focused primarily on cleanliness and infection control procedures) falls under MOHP, and administrative and financial supervision is handled by MOSS. In addition, they are monitored by central and local supervisors affiliated with the NGO itself.

Most NGO clinics provide FP as well as MCH care, treatment of infertility and premarital counseling. In addition, some EFPA- or CFPA-affiliated clinics provide cancer screening services as well as a health services package for young people that includes: (1) information and counseling on SRH, (2) FP services for young married couples, (3) counseling on healthy nutrition, (4) antenatal and delivery care, (5) management of pubertal health problems, and (6) counseling and treatment of sexually transmitted infections (Hafez, Oraby and Soliman, 2008). NGO clinics that are affiliated with CEOSS and the Coptic Church and some CDA clinics provide a range of social services besides $\mathrm{MCH}$ and FP services, including literacy classes, livelihood programs, and day care services. Most NGO clinics have strong links with the communities through outreach workers, who usually come from the same community. Clinics that provide health services for youth have peer educators who reach out to young people at 'hot spots' and raise awareness about a wide range of SRHrelated issues such as HIV, female genital mutilation/cutting, and other topics.

Doctors (and sometimes nurses) who work at NGO clinics are mostly seconded from MOHP on a full- or a part-time basis, while some doctors are fully employed by MOHP but work at an NGO clinic in the afternoon or evening (i.e. after MOHP work hours). Doctors seconded by MOHP receive their salary from MOHP, plus a portion of the consultation fees charged by the NGO for each client they see.

There is wide variation among NGO clinics with regard to work hours, which depend largely on the availability of physicians as well as client load. Most physicians work Saturday through Thursday from 9:00 am to 2:00 pm, while a few have evening hours from 5:00 pm to 8:00 pm. The Service Provision Assessment (SPA) of 2004 showed that 28 percent of NGO clinics do not offer family planning services on a daily basis (Ministry of Health and Population, El Zanaty Associates and ORC Macro, 2005). Also, SPA pointed out several gaps in quality of FP services offered in NGO clinics compared to public facilities, including lack of service delivery guidelines, visual aids to support FP counseling and items of infection control.

NGOs obtain family planning methods at a subsidized price from El-Gomhoreya Pharmacy (a state-owned pharmacy), after securing MOHP approval. Thus, they offer the same methods that are offered by MOHP 
clinics, with the exception of Implanon, which they are not allowed to offer. ${ }^{15}$ NGO clinics are supposed to sell family planning methods at the same price as MOHP, but they are allowed to charge higher consultation and insertion fees (see Annex III for a list of prices at public, private and NGO clinics). Consultation fees range from EGP 10 to EGP 45 (US\$1.25-5.60), while IUD insertion fees range from EGP 35 to EGP 70 (US\$4.40-8.80). Those fees are substantially lower than those charged by private physicians in their clinics.

Sources of funding for NGOs come from local or international donations, MOHP, MOSS, and service revenue. MOSS provides limited cash or in-kind contributions to NGOs, while MOHP provides in-kind contributions through provision of equipment (e.g. ultrasound machines), FP commodities, IEC material, or through secondment of physicians and nurses. Some NGOs receive credit (as a loan) from the Social Fund for Development (SFD), mainly for renovation of clinics, while others receive grants from SFD or international organizations to support other activities (e.g. livelihood programs).

Most FGD participants who received FP services from an NGO facility appreciated the quality of care they received at those clinics, as well as the low cost of services. One client mentioned that she continues to go to the same clinic even after changing her residence because she trusts the doctor who works in that clinic. Another client said, "I used to pay EGP 12 to get an injection at a private doctor's, then I found it for EGP 3.5 at the NGO center and for EGP 1.0 at the government, so I decided to get it at the NGO center."

\section{Pharmacies}

According to CAPMAS (2014) statistics, there are more than 60,000 private pharmacies across Egypt. Pharmacies are found in both rural and urban areas, but tend to be concentrated in urban areas. On average, each pharmacy serves a population of 2,022 inhabitants of the catchment area, with a range of 11,087 in urban Lower Egypt to 9,936 inhabitants in rural Upper Egypt. Pharmacies do not need to be owned by a pharmacist, but Egyptian law requires that a pharmacy be managed by a pharmacist with a minimum of one year of experience in pharmaceutical work (with no special training apart from a degree in pharmacy). It is noteworthy that on many occasions the pharmacist is not available at the pharmacy and medications are sold by an assistant who may not have a pharmacy degree. The working hours of pharmacies vary, with some open 24 hours while others close at night and take one day off each week.

Pharmacists sell a wide range of products, including prescription and non-prescription ${ }^{16}$ medications, FP methods, cosmetics, and other items. The following FP methods are sold at private pharmacies: COCs, mini pills, one-month injectables, IUDs, and condoms. Emergency contraceptive pills (ECPs) are available on an irregular basis, while IUDs are more likely to be found in pharmacies that have Ob/Gyn doctors in the same vicinity, to ensure they will be purchased by clients. According to one pharmacist in Cairo, only one of type of IUD (Mirena) is being distributed to pharmacies, while Copper T brands go directly to doctors.

Prices of family planning methods are fixed at all pharmacies, as set by the government. Appendix IV shows the prices of various FP methods that are offered at pharmacies.

Pharmacists who participated in this study stated that they maintain good relations with their customers and their families. They indicted that women trust pharmacists, especially when they have been working in the neighborhood for many years. They are consulted by women who have recently delivered a baby, those who forgot to take their pill, or who are experiencing problems with family planning methods. In the latter case,

\footnotetext{
15 According to MOHP regulations, Implanon can be only inserted at selected urban health centers or hospitals that have a trained $\mathrm{OB} / \mathrm{Gyn}$ or RH specialist.

16 Apart from selected narcotics which require a medical prescription, all medications can be sold over the counter in Egypt.
} 
pharmacists claim that they advise women to consult their doctor. Women who participated in FGDs appreciated the convenience that the pharmacy provides. "You find a pharmacy every 100 meters", as one woman put it. Also, a few women in urban areas believed that POPs that are offered in public facilities are of lesser quality than those offered at pharmacies; hence they prefer to buy them at pharmacies.

The main source of information about new FP methods for pharmacists is medical representatives. Pharmacists who participated in our qualitative study indicated that they did not receive any training in family planning, although some of the older pharmacists indicated that they received training several years ago through the 'Ask - Consult' network.

\section{THE PRIVATE SECTOR AS A PROVIDER OF FP SERVICES}

\section{Where do Various Subgroups of Women go for FP Services?}

According to EDHS 2014, 56.7 percent of current users of modern FP obtained their method from a public facility (i.e. rural or urban health unit, general or district hospital, health insurance organization, university or teaching hospital, mobile clinic or another government source). Fewer than half of current users of modern FP methods (43.1 percent) obtained their method at a private facility (i.e. private clinic/ hospital, pharmacy, NGO clinic, mosque or church health unit or a non-medical source). A few users ( 0.2 percent) could not identify the type of service provider where they obtained their current method or had a missing response. Table 1 shows that 21.7 percent obtained their method at a private clinic or hospital, 20.5 percent obtained it at a pharmacy, and 0.6 percent obtained their FP method at an NGO facility.

Secondary analysis of EDHS 2014 data reveals marked variations in public and private sector use patterns by client characteristics, as well as type of method used. Table 1 shows that use of public sector facilities tends to be highest among women with five or more children (62.7\%), women in rural Upper Egypt (64.4\%), users of three-month injectables (91.0\%), Implanon (68.0\%), and IUDs (63\%), those with no education and those in the poorest two wealth quintiles $(66.8 \%$ and $68.1 \%$, respectively). In the meantime, more than one-third $(39.4 \%)$ of women in the richest wealth quintile received their modern FP method at a public sector facility. It is noteworthy that $34.3 \%$ of women who obtained their FP method at a public facility belong to the highest two wealth quintiles (data not shown).

Use of private clinics and hospitals is highest among women in Frontier governorates (26.8\%), users of female sterilization (78.7\%), women with above secondary education (39.4\%), and women in the highest wealth quintile $(33.9 \%)$. Use of private clinics and hospitals tends to be lower among users of oral pills $(1.6 \%)$, three-month and one-month injectables (2.2\% and $2.9 \%$, respectively), and male condoms $(1.4 \%)$, as well as among residents of rural Upper Egypt (14.5\%). The largest percentage of pharmacy users was recorded among women with no living children (100\%), ${ }^{17}$ those who use the pill, condoms, or one-month injectables $(63.5 \%, 74.9 \%$ and $50.0 \%$, respectively), and those who live in Frontier governorates and urban Lower Egypt (29.6\% and 27.2\%, respectively). Use of NGOs as a source of FP is generally low (0.6\%), but tends to be higher among women who live in urban Lower Egypt $(1.2 \%)$ and those who are using an IUD $(1.0 \%)$.

17 Only $0.1 \%$ of women with no living children used contraception, and all those women used oral pills. 
TABLE 1 | PERCENT DISTRIBUTION OF SOURCE OF FP METHOD BY SELECTED CHARACTERISTICS OF WOMEN (SOURCE: EDHS, 2014)

\begin{tabular}{|c|c|c|c|c|}
\hline & Public & Private doctor & Pharmacy & NGO \\
\hline \multicolumn{5}{|l|}{ Age } \\
\hline $15-19$ & 59.5 & 21.1 & 19.4 & 0.0 \\
\hline $20-24$ & 54.2 & 19.5 & 25.1 & 0.8 \\
\hline $25-29$ & 55.7 & 19.0 & 24.4 & 0.4 \\
\hline $30-34$ & 57.0 & 21.4 & 20.7 & 0.6 \\
\hline $35-39$ & 58.0 & 21.9 & 19.4 & 0.6 \\
\hline $40-44$ & 58.5 & 23.9 & 16.3 & 0.7 \\
\hline $45-49$ & 56.9 & 26.1 & 16.0 & 0.7 \\
\hline \multicolumn{5}{|c|}{ Number of living children } \\
\hline 0 & 0.0 & 0.0 & 100.0 & 0.0 \\
\hline $1-2$ & 52.8 & 22.4 & 23.5 & 0.8 \\
\hline $3-4$ & 58.3 & 21.7 & 18.9 & 0.5 \\
\hline $5+$ & 62.7 & 18.9 & 17.6 & .2 \\
\hline \multicolumn{5}{|l|}{ Residence } \\
\hline Urban Governorates & 50.5 & 28.0 & 20.9 & 0.6 \\
\hline Urban Lower Egypt & 42.5 & 28.8 & 27.2 & 1.2 \\
\hline Rural Lower Egypt & 60.9 & 21.0 & 17.2 & 0.6 \\
\hline Urban Upper Egypt & 60.9 & 21.0 & 17.2 & 0.6 \\
\hline Rural Upper Egypt & 64.4 & 14.5 & 20.3 & 0.1 \\
\hline Frontier Governorates & 43.1 & 26.8 & 29.6 & 0.5 \\
\hline \multicolumn{5}{|l|}{ FP method } \\
\hline IUD & 63.0 & 35.7 & 0.1 & 1.0 \\
\hline Oral pills & 34.7 & 1.6 & 63.5 & 0.0 \\
\hline Three-month injectables & 91.0 & 2.2 & 5.7 & 0.1 \\
\hline One-month injectables & 46.1 & 2.9 & 50.0 & 0.0 \\
\hline Female sterilization & 21.3 & 78.7 & 0.0 & 0.0 \\
\hline Male condoms & 23.7 & 1.4 & 74.9 & 0.0 \\
\hline Implanon & 68.0 & 32.0 & 0.0 & 0.0 \\
\hline \multicolumn{5}{|l|}{ Education } \\
\hline No education & 69.0 & 14.8 & 15.2 & 0.4 \\
\hline Primary & 65.1 & 18.1 & 16.6 & 0.2 \\
\hline Secondary & 55.9 & 20.8 & 22.2 & 0.7 \\
\hline Above Secondary & 33.5 & 39.4 & 26.1 & 0.7 \\
\hline \multicolumn{5}{|l|}{ Work status } \\
\hline Working for cash & 53.1 & 21.1 & 21.8 & 0.3 \\
\hline Not working for cash & 57.6 & 24.4 & 20.3 & 0.6 \\
\hline
\end{tabular}




\begin{tabular}{|c|c|c|c|c|}
\hline \multicolumn{5}{|c|}{ Wealth quintile } \\
\hline Lowest & 66.8 & 17.3 & 14.8 & 0.7 \\
\hline Second & 68.1 & 16.2 & 15.3 & 0.2 \\
\hline Middle & 58.6 & 19.5 & 20.7 & 0.4 \\
\hline Fourth & 54.0 & 20.5 & 24.7 & 0.6 \\
\hline Highest & 39.4 & 33.9 & 25.4 & 0.8 \\
\hline Total & 56.7 & 21.7 & 20.5 & 0.6 \\
\hline
\end{tabular}

The results from 2014 EDHS shown in Table 1 are consistent with reports from the women and providers who participated in this qualitative study, as well as the results of previous studies showing that certain methods were available in private facilities but not in public facilities and vice versa. For example, threemonth injectables and subdermal implants are imported exclusively for MOHP and hence are only offered in public facilities. Three-month injectables may be offered at NGO clinics, but are not supposed to be sold in pharmacies. The fact that one-third of women indicated that they obtained their subdermal implants at a private facility may suggest seepage of methods from the public to the private sector as a result of the dual affiliation of most physicians in Egypt. Female sterilization (i.e. tubal ligation) is not offered in public family planning clinics, only in hospitals to women who have serious medical conditions that contraindicate pregnancy. $18 \mathrm{~A}$ woman who wants to undergo female sterilization must obtain a medical certificate from two doctors (other than the one who will perform the procedure) indicating that pregnancy could pose a risk to her life, she and her husband must provide written consent, and the procedure must be performed more than two weeks after obtaining consent. Thus, women who are seeking female sterilization may prefer to go through a private doctor who may be more flexible on the above requirements.

Women from rural and poor urban areas who participated in the FGDs for this study said they obtained their methods at public clinics or pharmacies because of their low price. Most of them indicated that even though private doctors may offer better quality, many women cannot afford their high fees. They also said that clients of private doctors were women who were wealthy enough to afford their fees, were not used to receiving public services, or who had special medical conditions requiring a higher quality of care.

In interviews, private physicians confirmed that most of their family planning customers were women who belonged to the middle and upper-middle class and who had secondary or university education. An earlier study of private sector providers showed that use of the private sector for FP was higher among women with secondary or above education (55\%), who worked for cash (53\%), or who lived in urban Lower Egypt (58\%) or in urban Upper Egypt (57\%) (Cairo Demographic Center, 2002).

Private doctors mostly prescribed IUDs and, to a lesser extent, injectables to their clients. A few private physicians mentioned that some clients come to them requesting tubal ligation (female sterilization), but they prefer not to provide it to them "because it is haram" (forbidden by Islam).

NGO providers indicated that their clients were mostly poor and lower-middle class women. Apart from their FP clients, some of their clients were young, unmarried women who sought advice about menstrual problems, while others came to seek reassurance that their hymen was intact. Most women who participated in the FGDs indicated that NGOs provided services that were as good as the private sector, but at more affordable prices.

18 According to Islamic law, terminal FP methods are only sanctioned when the life of the mother is clearly threatened by an additional pregnancy. 
Pharmacists said their customers came from all social classes. They mostly prescribed oral pills to women who sought their advice about FP. Several women in the FGDs, especially in Assiut, mentioned that their husbands bought the pills for them at the pharmacy. This was confirmed by pharmacists in Assiut, as well as by an earlier study of private FP providers that revealed that $40 \%$ of women in urban Upper Egypt had never visited a pharmacy (Cairo Demographic Center, 2002). A few participants in Cairo and urban areas believed that POPs offered in public facilities were not effective and they therefore preferred to get them at private pharmacies.

A few male pharmacists said they felt too shy to mention the male condom to their female clients, but said they had no problem discussing it with their male customers if they asked for it. Interestingly, more pharmacists in Assiut than in Cairo or Gharbeya mentioned receiving male customers who specifically asked for the male condom. EDHS 2014 data do not show higher levels of condom use in Assiut compared to other governorates, which may suggest those condoms are used for non-FP purposes (e.g. to have sex with their wife during her menstrual period).

The secondary analysis of EDHS 2014 suggests a higher probability of use of private sector sources in Frontier governorates, which might be due to a shortage of public physicians in those governorates, as revealed by a recent study of the reproductive health needs of young people in Bedouin communities (Fateem and Wahba, 2012). There may also be specific quality of care issues (such as non-use of gloves for IUD insertion or lack of a sterile syringe or an injection) in Frontier governorates (Health Systems 20/20 project, 2012).

\section{Trends in Private Sector Use (1995 - 2014)}

Trend analysis of FP method sources using EDHS data revealed an overall decrease in reliance on private sector sources from 1995 to 2014. In 1995, 64 percent of married women currently using a modern method relied on private sector sources. That percentage decreased over the intervening years to reach 43 percent in 2014, albeit with a slight increase between 2008 and 2014 (40 percent to 43 percent) (Figure 2). On the other hand, private sector use by IUD users increased slightly between 2008 and 2014 (from 33.3\% to 37.1\%). In an effort to identify reasons for decreased reliance on the private sector, we examined trends in method mix. As shown in Table 2, the method mix has not changed significantly over the last 20 years, with the IUD being the most commonly used method, followed by pills and finally injectables.

Figure 3 shows that use of private physicians increased from 27.9\% in 1995 to a peak of 29.6 percent in 2000, and then steadily declined to a low of $21.7 \%$ in 201419 . Pharmacists' contributions also declined from $23 \%$ in 1995 to $15-16 \%$ in $2000 / 2008$, and increased to $20.5 \%$ in 2014 . However, the most remarkable change has been in the contribution of the NGO sector to FP service delivery; in 1995, about $10 \%$ of contraceptive users obtained their method at an NGO facility, but this percentage declined steadily until it reached $0.6 \%$ in 2014 . Figure 4 shows trends in NGO sector contributions between 1995 and 2014 by type of method. In 2014, 1\% of IUD users obtained their method at an NGO, compared to 13.1\% in 1995. A similar trend is observed among pill users, of whom $6.7 \%$ obtained their method at an NGO in 1995, compared to $0.1 \%$ in 2014 .

19 According to EDHS 2014, the distribution of source of modern FP method is as follows: public sector (56.7\%), private hospital/clinic $(21.7 \%)$, pharmacy $(20.5 \%)$, NGO facility $(0.6 \%)$, private non-medical source $(0.3 \%)$, don't know $(0.1 \%)$ and data not available $(0.1 \%)$. 
FIGURE 2 | TRENDS IN USE OF THE PRIVATE SECTOR AS A SOURCE OF MODERN FAMILY PLANNING METHODS (1995 - 2014)

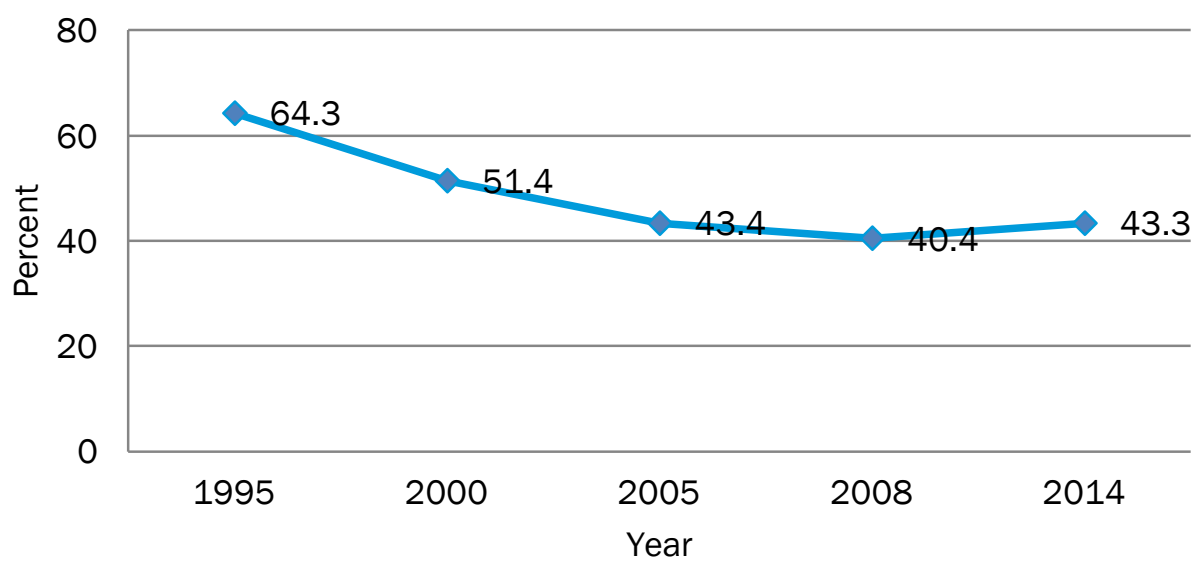

TABLE 2 | TRENDS IN FAMILY PLANNING METHOD MIX (1995 - 2014) SOURCE: EDHS DATA

\begin{tabular}{|c|c|c|c|c|c|}
\hline & 1995 & 2000 & 2005 & 2008 & 2014 \\
\hline Pill & 21.7 & 16.9 & 16.7 & 19.7 & 27.4 \\
\hline IUD & 62.6 & 63.4 & 61.5 & 59.8 & 51.4 \\
\hline Injectables & 5.0 & 10.9 & 11.9 & 12.3 & 14.5 \\
\hline Female sterilization & 1.1 & 1.4 & 1.3 & 1.0 & 1.2 \\
\hline Diaphragm/ jelly & 0.1 & 0.2 & 0 & 0 & 0.5 \\
\hline Implants & 0 & 0.2 & 0.8 & 0.5 & 0.5 \\
\hline Total modern method use & 35.7 & 48.6 & 56.6 & 57.6 & 56.7 \\
\hline
\end{tabular}


FIGURE 3 | TRENDS IN SOURCE OF FAMILY PLANNING METHODS (1995 - 2014)

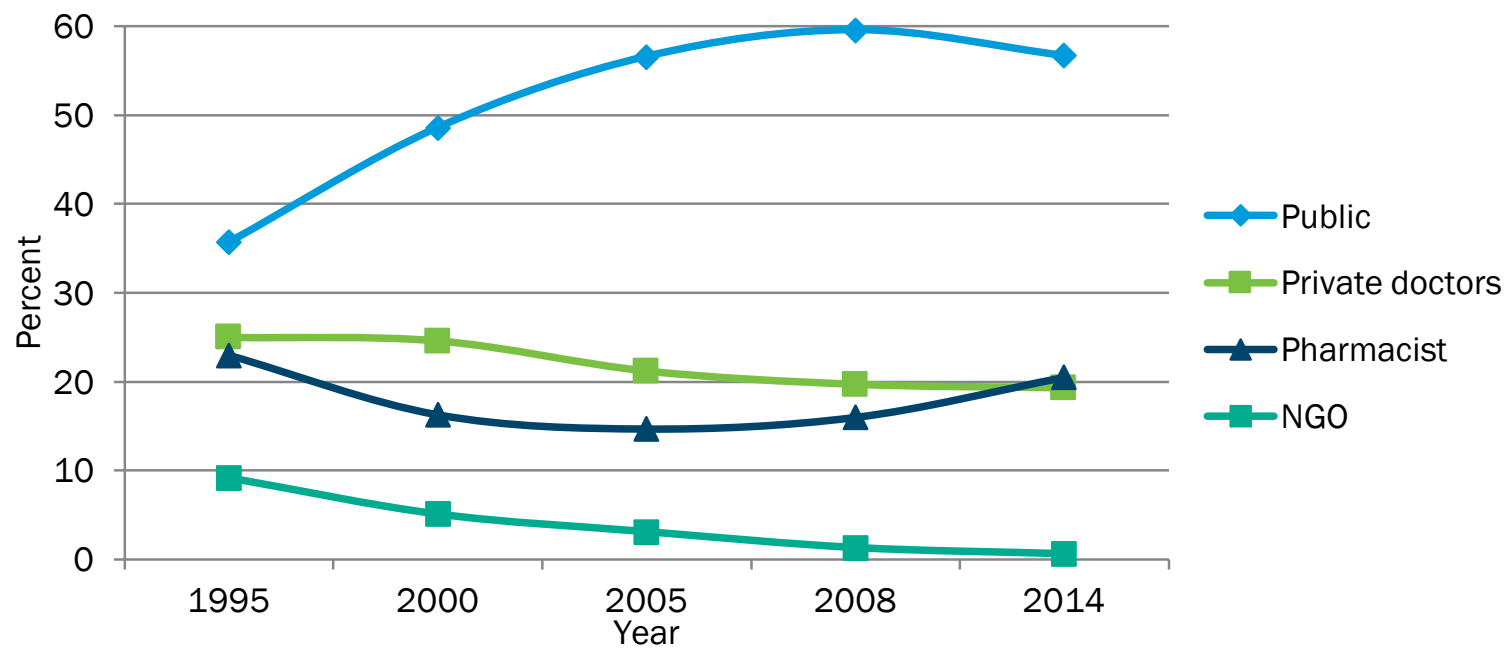

FIGURE 4 | TRENDS IN USE OF NGOS AS A FAMILY PLANNING METHODS SOURCE, BY TYPE OF METHOD (1995 - 2014)

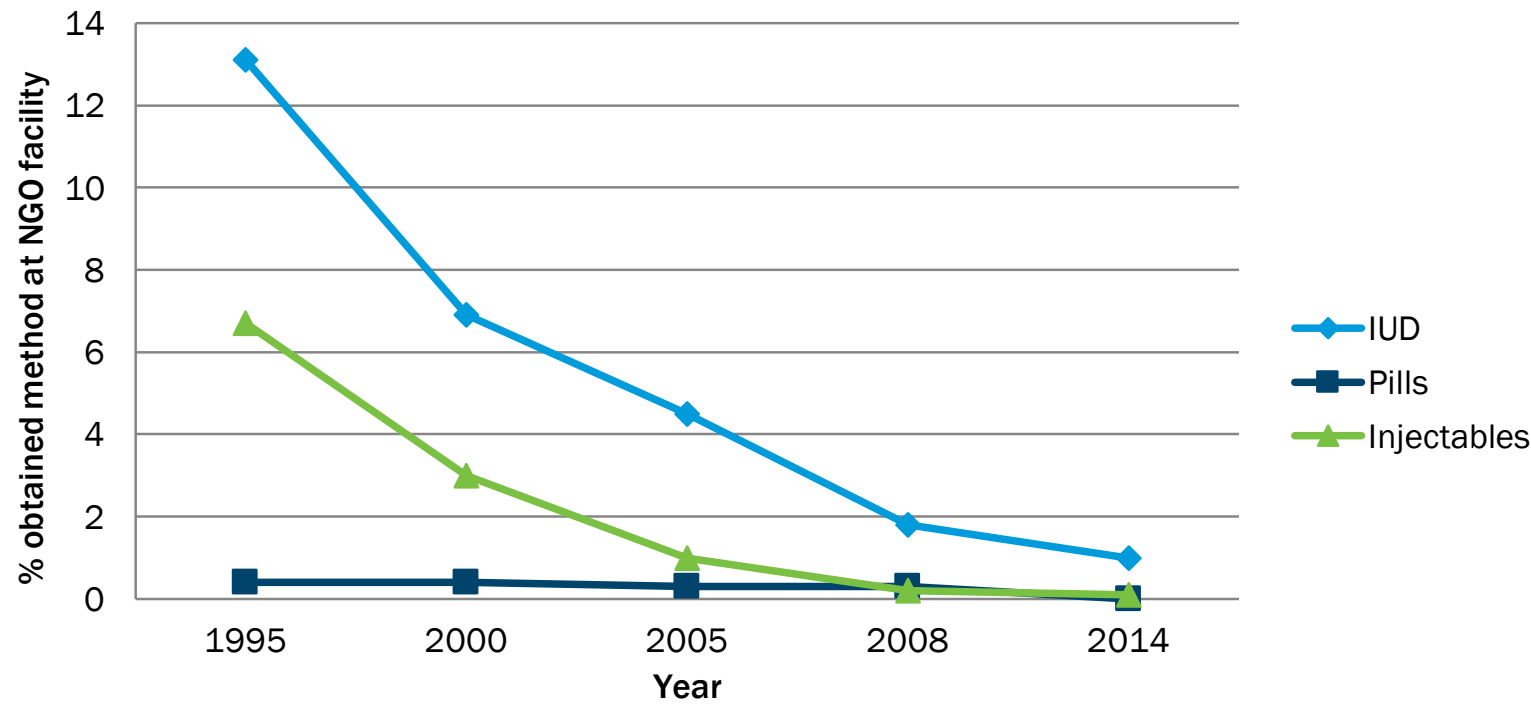




\section{THE PRIVATE SECTOR: CHALLENGES AND OPPORTUNITIES \\ What is Hindering the Private Sector from Playing a Greater Role? Provider, Client and Stakeholder Perspectives}

The dwindling role of the private sector in FP service delivery as demonstrated in the above section is the result of multiple and inter-related factors. This section highlights specific challenges mentioned by study participants and identified through the desk review.

\section{Limited contraceptive options and method stock-outs}

Pharmacists complained about stock outs of some methods, such as Copper T IUDs, ECPs, and foaming tablets, as well as a limited number of brands available for each method. Long and complex bureaucratic procedures discourage pharmaceutical companies and importers from introducing new methods to the Egyptian market. One official reported that her importing company wanted to import a three-month contraceptive injectable from Indonesia that is comparable to Depo-Provera (produced by Pfizer). However, their request was rejected by MOHP because Indonesia is not on the list of reference countries approved by the MOHP technical committee (see Annex V for list of reference countries). According to one official at a pharmaceutical company, if the exporting country is not on the reference list, the importer must provide additional documents and certifications, which are sometimes impossible to secure. Sino-implant was reportedly rejected by the CAPA because it was deemed "unnecessary" by the Committee, and China is not on the reference country list.

Current pricing policies also discourage pharmaceutical companies from manufacturing or importing contraceptives. According to study respondents affiliated with pharmaceutical companies, in many cases the price set by the Committee does not allow for a sufficient profit margin, which creates a disincentive for companies to import or manufacture the product.

Also, fixed profit margins and preset prices for different FP products and restrictions against increasing prices to cope with inflation rates and decreased value of Egyptian pound against US dollar have led importing companies to discontinue family planning methods that are not bringing in enough profit (e.g. the Copper $\mathrm{T}$ IUD and ECP). According to one official in the pharmaceutical industry, "the pricing committee has set the price of Depo-Provera at EGP 8.5 (i.e. \$1.10), while we buy it at $\$ 1.10, \ldots$ it is unrealistic because you still need to add taxes, shipping costs, margin of profit for importer, distributer and pharmacist..." Another official noted that pharmaceutical products were the only commodity whose price is fixed by the Egyptian government.

It was clear from interviews with stakeholders and providers that decisions by pharmaceutical distribution companies and product stocking decisions by pharmacists are made primarily on the basis of return on investment (i.e. business and profitability considerations). If a contraceptive is not bringing in sufficient profit, it will not be requested by pharmacists, and distribution and manufacturing companies will discontinue it.

Moreover, one NGO official complained about condom stock-outs at MOHP facilities and eventually at his NGO facilities. According to one key informant, the importation process for pharmaceutical products, including FP commodities, constitutes a bottleneck as it involves securing approvals for every shipment, routine inspection by CAPA and finally release of the product to the market. and hence constitutes a bottleneck. "Sometimes condoms are not available and this is a disaster... I end up buying from a private company and in that case I charge my clients a higher price [than] when I used to buy it from MOHP at EGP 1.0." 


\section{Low demand for FP methods}

Customer demand is the main determining factor for decisions related to stocking family planning products. According to study respondents, the phasing out of USAID support has contributed to the discontinuation of social marketing campaigns and has led to decreased awareness of new FP methods among both clients and providers. A trend analysis of EDHS data (1995-2014) showed a decline in women's exposure to FP messages through mass media from 100\% in 1995 to 47\% in 2014. In fact, previous social marketing campaigns rectified misconceptions about specific family planning methods and introduced new methods (e.g. condoms or foaming tablets). Lack of awareness of some methods (e.g. ECP), along with negative attitudes towards other methods (e.g. condoms), reduce the likelihood of physicians prescribing them or clients requesting them. Eventually, this leads to discontinuation of that method by the importing or distributing company. It was clear from FGDs with women that private physicians did not advise their patients to use FP, perhaps because of a financial disincentive (as fewer women will become pregnant and deliver babies). In fact, women who participated in the study mentioned that their main source of information about family planning was public providers, pharmacists, and other women; very few women mentioned private providers as their main source. According to one official in the pharmaceutical industry, private physicians do not play a proactive role in promoting family planning, but rather only respond to questions posed by their clients.

Although in the past state television provided free airtime to the national FP program, this is no longer the case, due to budget deficits experienced by state television, as well as the fact that pharmaceutical companies are seen as profit-making entities and hence are not eligible for free airtime. Also, with the increased privatization of the media industry, TV is now dominated by privately-owned satellite channels whose owners favor commercial advertising over public service announcements (USAID, 2011).

\section{Inadequate provider knowledge and skills}

The shortage of international funding, in conjunction with political transitions over the last five years, have led to discontinuation of FP training programs for physicians and pharmacists, contributing to their limited knowledge. Likewise, the NGO physicians included in this study said they have not received family planning training in almost ten years. The NGO physicians affiliated with clinics that provide 'youth friendly services' received more recent, donor-funded training, which briefly covered family planning among other topics.

In the meantime, coverage of family planning methods in medical and pharmacy schools is very limited and there are no opportunities for FP as part of continuing medical education (CME). Only senior doctors, such as university professors or consultants, receive newsletters from international associations (e.g. Royal College for Obstetrics and Gynecology) on a regular basis, while others must rely on medical representatives as their main source of information. Inadequate physician knowledge and misconceptions about some methods not only limit contraceptive options and quality of services for women but also indirectly affect pharmacists and the pharmaceutical industry, as doctors are unlikely to prescribe certain methods and sales of those methods remain low, eventually leading to their discontinuation.

Results of EDHS 2014 suggest that the quality of counseling offered by private doctors is reasonable, as 63\% of private physicians told clients about family planning methods other than the one they received and 52\% told them about side effects. However, there are anecdotal reports of private physicians advising women complaining of IUD side effects to take out the IUD and 'get some rest' before using another method (Nawar et al., 2004). Moreover, the quality of counseling offered by pharmacists is questionable, as EDHS 2014 has shown that 46.9 percent of pharmacy users were told about various FP methods, while 28.1 percent were told about method side effects. In fact, some MOHP officials attribute high discontinuation rates among pill users compared to IUD users (42\% compared to 14\%, respectively) (Ministry of Health and 
Population, El-Zanaty and Associates and ICF International, 2015) to inadequate counseling provided by pharmacists.

Reports by women and providers who participated in the qualitative study suggest serious knowledge gaps and misconceptions among private providers in relation to FP. FGDs participants in Assiut mentioned that their private doctors advised them against using subdermal implants because they could cause infertility, water retention, or "they could melt in a woman's body if she is exposed to heat of the oven," none of which is true. A private doctor in an interview expressed his disapproval of using family planning to delay the first pregnancy, saying, "What I cannot understand is people who just got married and want to use family planning ... this is wrong because she may not be able to get pregnant afterwards." Other doctors said they believed female sterilization and ECP were 'haram' (forbidden by Islam).

Absence of standard operating procedures for NGOs and private providers, combined with a lack of supervision and training, undermine the overall quality of FP services delivered in the private sector. There are also anecdotal reports from some study participants suggesting that non-pharmacists are sometimes involved in prescribing medications, including FP methods, to pharmacy customers, increasing the possibility for providing inaccurate information and services.

\section{Funding and staffing constraints for NGOs}

Lack of funding is the main challenge facing NGOs. Until 1997, the main source of funding for EFPA was IPPF, which covered salaries, equipment, and utilities. An earlier assessment of the cost-efficiency of FP and RH services at NGO clinics showed that fees paid by clients for FP or RH services do not cover the actual cost of those services, and that NGOs must therefore find other mechanisms to cover the deficit (El-Zanaty and Ramadan, 2002). However, funding from IPPF fell after 1997, which led to the resignation of some physicians and nurses. Moreover, MOSS decreased the amount of funds to NGOs to a minimum. To maintain the low cost of their services, NGOs often rely on donations or international funds. However, laws governing the operations of NGOs have made it very difficult for them to receive external funds and hence sustain their activities. ${ }^{20}$ Lack of funds undermines the availability of equipment and supplies, and has a negative impact on the overall quality of services. According to one NGO official, "To provide quality services you need good infrastructure ... a clinic could only have one room for examination thus counseling takes place in the waiting area where there is no visual or auditory privacy."

In terms of staffing, in the past, female physicians were seconded from MOHP to NGOs, with their salary fully paid by MOHP. However, the Civil Service law, which was in effect between July 2015 and January 2016, allowed secondment of physicians to NGOs but required the receiving organization to pay the salary of the employee. This new condition has made it difficult for NGOs to afford enough doctors to staff their clinics. ${ }^{21}$ Also, as the MOHP is experiencing difficulty retaining female doctors willing to work in rural areas, especially rural Upper Egypt, MOHP is increasingly declining NGOs requests for seconded doctors. It is reported that several clinics affiliated with EFPA had to close down due to shortages of female physicians. One NGO official added that every time his NGO trains physicians, they go back to MOHP and he has to train a new batch, posing an obvious burden on their already limited budget.

\section{Cost of service}

Private physicians have a reputation among FGD participants as being too expensive and profit-driven. Some women gave examples of private physicians who pushed women to undergo C-sections, while others

${ }^{20}$ Law number 84 (2002)

${ }^{21}$ The Civil Service Law number 18 (2015) was rejected by the Egyptian Parliament in January 2016. 
persuaded their clients to insert more expensive IUDs when other types of IUDs were equally good. This sentiment expressed by women in the FGDs is reflected by others in society: it is not uncommon to see reference in mass media to the private sector and business owners as greedy, corrupt, and disloyal to the national good.

\section{Private sector fragmentation}

The private FP sector is composed of separate entities and lacks a common platform that would bring them together. They are seldom invited to participate in national FP committees and as a result their voice is not heard by government officials. One senior MOHP official said, "the private sector has no syndicate or association to talk to ... there are no representatives for the private sector."

\section{Bureaucratic procedures and restrictive policies}

Pharmaceutical companies complained about long and complex procedures that must be followed to register a FP commodity. Although the registration process is supposed to be officially completed in six months, it often takes up to two years, with some commodities failing to receive approval for registration, for no valid reason. According to several study participants, the fact that drug approvals are issued by MOHP and not an independent entity like the Food and Drug Administration in the United States makes the process vulnerable to frequent change of policies and procedures with each change of minister. In fact, there have been three ministerial decrees since 2009, each of which changed the documents required for the registration process.

Bureaucratic procedures pose a significant barrier for the private sector to become a supplier for the MOHP, as procurement must go through a complicated and time-consuming bidding process. One MOHP official complained that these lengthy procedures sometimes result in losing the funds assigned for purchasing contraceptives, if the fiscal year ends before completion of the procurement process.

Moreover, like many other private sector companies, the FP pharmaceutical industry in Egypt has been negatively affected by policy distortions, inefficient incentives, an unclear taxation system, and restrictions on availability of hard currency. Each of these issues have limited their productivity and inhibited their effective competitiveness.

\section{Competition from the public sector}

The relationship between the public and private sector tends to be more competitive than complementary. With MOHP's highly subsidized rates, widespread coverage in most governorates, and relatively good quality of services, many women do not have a strong reason to go to the private sector for family planning services. This creates problems for the long-term survival of the private sector. Restricting access to certain FP methods (e.g. three-month injectables and Implanon) to only public facilities further limits the private sector's ability to play a role. Moreover, some NGO officials believe MOHP intends to micromanage and undermine NGOs and confine their role to conducting awareness-raising activities. One NGO official gave an example of mobile clinics affiliated with MOHP providing free FP right next to an NGO clinic, when mobile clinics are supposed to provide services to women in deprived areas. In fact, MOHP regulations specify that a mobile clinic should be stationed no less than three kilometers from a government clinic, but do not mention a minimum distance from an NGO or private facility. On the other hand, the MOHP officials believe that the private sector is taking away their staff and subsidized commodities while contributing less than $1 \%$ of the overall FP market share. 


\section{Windows of Opportunity for Increased Involvement of the Private Sector}

\section{Increased market size}

Currently, more than 16 million women in Egypt have a demand for contraception (i.e. are either using contraception or have an unmet need for family planning). Women with unmet need for FP are those who wish to postpone the next pregnancy or to stop childbearing altogether but who are not using contraception, while women with met need are those who are currently using FP. Of that 16 million women, more than 2.8 million have an unmet need (i.e. are unable to satisfy their demand). Women with unmet need constitute $12.6 \%$ of married women of reproductive age (Table 3). Opportunities for the private sector in family planning can be found across the whole spectrum of demand, from expanding contraceptive access to the 2.8 million women with unmet need to more effectively meeting the needs of the 12 million women currently using contraception, including those who receive services from the public sector but who may want to switch to the private sector. A large segment of these women could be better reached by the private sector, if the private and public sectors work together to define the "market" for each sector (see Recommendations Section for more on this).

Table (3) shows that one-third of women with unmet need live in urban areas (11\% in urban governorates, 9\% in urban Lower Egypt and 12\% in urban Upper Egypt); half of them have completed secondary or higher education and more than one-third (35\%) belong to the two highest wealth quintiles. The above subgroups of women could be easily targeted by the private sector, especially private and NGO clinics. Women with unmet need in the highest two quintiles alone total more than one million women. Moreover, pharmacies may have the opportunity to reach women who reside in rural areas, who constitute two-thirds of women with unmet need.

TABLE 3 | NEED AND DEMAND FOR FAMILY PLANNING AMONG CURRENTLY MARRIED WOMEN

\begin{tabular}{|c|c|c|c|c|c|c|}
\hline & \multicolumn{2}{|c|}{ Unmet need for FP } & \multicolumn{2}{|c|}{$\begin{array}{l}\text { Met need for FP } \\
\text { (currently using) }\end{array}$} & \multicolumn{2}{|c|}{ Total demand for $\mathbf{F P}^{22}$} \\
\hline & No. & $\%$ & No. & $\%$ & No. & $\%$ \\
\hline \multicolumn{7}{|l|}{ Age } \\
\hline $15-19$ & 73,834 & 2.6 & 168,178 & 1.3 & 242,833 & 1.5 \\
\hline $20-24$ & 360,484 & 12.7 & $1,386,224$ & 10.5 & $1,746,708$ & 10.9 \\
\hline $25-29$ & 603,288 & 21.3 & $2,798,446$ & 21.3 & $3,401,734$ & 21.3 \\
\hline $30-34$ & 586,643 & 20.7 & $2,828,144$ & 21.5 & $3,414,787$ & 21.3 \\
\hline $35-39$ & 454,764 & 16.1 & $2,620,306$ & 19.9 & $3,075,070$ & 19.2 \\
\hline $40-44$ & 354,518 & 12.5 & $2,013,662$ & 15.3 & $2,368,180$ & 14.8 \\
\hline $45-49$ & 399,015 & 14.1 & $1,335,147$ & 10.3 & $1,754,162$ & 11.0 \\
\hline \multicolumn{7}{|l|}{ Residence } \\
\hline Urban & 919,258 & 32.5 & $4,775,468$ & 36.3 & $5,702,516$ & 35.6 \\
\hline Rural & $1,912,115$ & 67.5 & $8,383,889$ & 63.7 & $10,310,713$ & 64.4 \\
\hline \multicolumn{7}{|l|}{ Place of residence } \\
\hline Urban Governorates & 310,906 & 11.0 & $1,753,397$ & 13.3 & $2,064,302$ & 12.9 \\
\hline
\end{tabular}

22 Total demand is the sum of unmet need and met need. 


\begin{tabular}{|c|c|c|c|c|c|c|}
\hline Urban Lower Egypt & 261,192 & 9.2 & $1,497,663$ & 11.4 & $1,758,856$ & 11.0 \\
\hline Rural Lower Egypt & 896,984 & 31.7 & $5,582,198$ & 42.4 & $6,479,182$ & 40.5 \\
\hline Urban Upper Egypt & 334,630 & 11.8 & $1,459,977$ & 11.1 & $1,797,086$ & 11.2 \\
\hline Rural Upper Egypt & $1,004,857$ & 35.5 & $2,760,401$ & 21.0 & $3,765,258$ & 23.5 \\
\hline $\begin{array}{l}\text { Frontier } \\
\text { Governorates }^{23}\end{array}$ & 22,379 & 0.8 & 111,895 & 0.9 & 134,274 & 0.8 \\
\hline \multicolumn{7}{|l|}{ Education } \\
\hline No education & 730,361 & 25.7 & $3,110,604$ & 23.6 & $3,840,966$ & 24.0 \\
\hline Some primary & 189,810 & 6.7 & 765,879 & 5.8 & 955,689 & 6.0 \\
\hline $\begin{array}{l}\text { Primary complete/some } \\
\text { secondary }\end{array}$ & 506,732 & 17.8 & $2,148,699$ & 16.3 & $2,655,431$ & 16.6 \\
\hline Secondary complete/higher & $1,414,702$ & 49.8 & $7,145,446$ & 54.3 & $8,548,159$ & 53.4 \\
\hline \multicolumn{7}{|l|}{ Wealth quintiles } \\
\hline Lowest & 613,911 & 21.7 & $2,228,418$ & 16.9 & $2,842,330$ & 17.8 \\
\hline Second & 655,865 & 23.1 & $2,435,446$ & 18.5 & $3,091,311$ & 19.3 \\
\hline Middle & 561,876 & 19.8 & $3,006,798$ & 22.8 & $3,568,675$ & 22.3 \\
\hline Fourth & 520,984 & 18.4 & $2,806,742$ & 21.3 & $3,327,726$ & 20.8 \\
\hline Highest & 482,298 & 17.0 & $2,692,102$ & 20.4 & $3,174,400$ & 19.8 \\
\hline EDHS 2014 & $2,835,000$ & 12.6 & $13,162,500$ & 58.5 & $15,997,500$ & 71.1 \\
\hline EDHS 2008 & $2,189,210$ & 11.6 & $11,380,010$ & 60.3 & $13,569,220$ & 71.9 \\
\hline EDHS 2005 & $2,207,240$ & 12.3 & $10,623,400$ & 59.2 & $12,830,640$ & 71.5 \\
\hline
\end{tabular}

\section{Favorable Attitudes but Knowledge Gaps Exist}

Overall, women and men in Egypt have favorable attitudes about FP use. The Egypt Health Issues Survey (EHIS) demonstrates that 90.3 of women and 87.1 of men (15-49 years old) approve of a couple using FP after the first birth (Ministry of Health and Population [Egypt], El-Zanaty and Associates [Egypt], and ICF International, 2015). Thus, private sector physicians or pharmacists may not find it difficult to promote FP for birth spacing among married couples seeking their services. However, knowledge gaps exist, especially among young men and women (Table 4). According to EHIS results, 53 of women 15-49 years know the male condom, and less than one in eight men and women know about ECPs (14.7 and 11.5, respectively). Addressing knowledge gaps would offer more contraceptive choices to Egyptian couples, and eventually lead to increased adoption of family planning.

\footnotetext{
${ }_{23}$ Does not include North and South Sinai governorates.
} 
TABLE 4 | PERCENTAGE OF WOMEN AND MEN AGE 15-49 WHO KNOW A FAMILY PLANNING METHOD, BY SPECIFIC METHOD ACCORDING TO AGE

SOURCE: EHIS, 2015

\begin{tabular}{|c|c|c|c|c|c|c|}
\hline \multirow[b]{2}{*}{ Method } & \multicolumn{3}{|c|}{$\begin{array}{l}\text { Percentage of women } \\
\text { knowing method }\end{array}$} & \multicolumn{3}{|c|}{$\begin{array}{l}\text { Percentage of men knowing } \\
\text { method }\end{array}$} \\
\hline & $15-24$ & $25-49$ & $\begin{array}{l}\text { Total } \\
15-49\end{array}$ & $15-24$ & $25-49$ & $\begin{array}{l}\text { Total } \\
15-49\end{array}$ \\
\hline Any method & 96.6 & 99.9 & 98.8 & 89.4 & 99.3 & 95.9 \\
\hline Any modern method & 96.6 & 99.9 & 98.8 & 89.4 & 99.3 & 95.9 \\
\hline Pill & 95.3 & 99.7 & 98.2 & 86.3 & 98.2 & 94.1 \\
\hline IUD & 91.9 & 99.4 & 96.9 & 78.7 & 98.0 & 91.4 \\
\hline Injectables & 94.9 & 99.7 & 98.2 & 85.4 & 98.4 & 94.0 \\
\hline Implants & 66.7 & 87.8 & 80.8 & 47.7 & 73.9 & 64.9 \\
\hline Diaphragm/foam/jelly & 16.2 & 34.8 & 28.6 & 10.7 & 28.7 & 22.5 \\
\hline Condom & 34.0 & 62.6 & 53.2 & 45.0 & 74.4 & 64.4 \\
\hline Female sterilization & 54.1 & 74.4 & 67.7 & 42.5 & 63.7 & 56.5 \\
\hline Male sterilization & 10.2 & 15.5 & 13.8 & 10.8 & 19.0 & 16.2 \\
\hline Emergency contraception & 8.5 & 17.8 & 14.7 & 3.3 & 15.8 & 11.5 \\
\hline Any traditional method & 60.6 & 85.6 & 77.4 & 46.9 & 75.6 & 65.8 \\
\hline Periodic abstinence & 23.2 & 44.5 & 37.5 & 12.8 & 36.6 & 28.4 \\
\hline Withdrawal & 24.3 & 51.9 & 42.8 & 30.6 & 59.9 & 49.9 \\
\hline Prolonged breastfeeding & 57.2 & 81.2 & 73.3 & 34.8 & 63.7 & 53.9 \\
\hline Other & 0.0 & 0.2 & 0.1 & 0.0 & 0.0 & 0.0 \\
\hline Number & 2,611 & 5,295 & 7,906 & 2,147 & 4,146 & 6,293 \\
\hline
\end{tabular}

\section{Method-related Unmet Need for FP}

According to EDHS 2014, the most frequent reason (63.8) for non-use of family planning among women who want to postpone their next pregnancy or stop child bearing are related to fertility (e.g. infrequent sex, sub-fecundity, and breastfeeding). Greater availability of barrier methods such as the diaphragm, vaginal suppositories, and emergency contraceptive pills in the private sector could address the needs of women who have infrequent sex or who are sub-fecund. On the other hand, for women who are breastfeeding, there is a wide range of family planning methods that are available at both public and private sectors. The private sector could capitalize on addressing these needs when providing other services to these women, including addressing misconceptions about breastfeeding as a FP method and offering these women other FP methods if they do not meet the criteria for LAM.

The second most common reason for nonuse pertains to women's concern about method side effects (32.9). With adequate training, private physicians might have a comparative advantage over public physicians and pharmacists in addressing these concerns, as they are seen as more competent and knowledgeable than public providers. Private physicians could capitalize on visits during which they provide other services to these women to raise the topic of family planning.

\section{Missed Opportunities}

Antenatal care, delivery, and child health care visits are a few of the opportunities that the private sector can capitalize on in terms of FP. Secondary analysis of EDHS 2014 revealed that 88 of women with a demand for 
FP received antenatal care (ANC) at a private facility and more than one-third (39) delivered at a private facility. Women in the highest quintile, those with secondary or higher education, those who live in Lower Egypt and those who were having their first, second or third child were more likely to deliver in a private facility. Moreover, more than half of women (52) in Egypt had their last delivery by Caesarean section (Csection); approximately two-thirds of deliveries attended by private physicians are performed by $\mathrm{C}$-section. Although such high rates of $\mathrm{C}$-section deliveries raise questions about client safety and cost to the client, family and health system, C-section deliveries provide a good opportunity for providing FP counseling and postpartum contraception especially IUD insertion. Through adequate counseling during ANC visits, women could be prepared for postpartum contraception and for immediate postpartum IUD insertion; if that is the method they choose.

In terms of child health, nine out of 10 Egyptian children are fully immunized. Most families get their children immunized at public facilities, thus the private sector does not have a significant role to play in reaching mothers through immunization sessions. However, just more than half (52) of children who had acute respiratory infection symptoms were taken to a private physician (Ministry of Health and Population, El-Zanaty and Associates and the DHS Program, 2015), which offers an opportunity to bring up FP with mothers especially when the doctor is a GP.

Pharmacists could also initiate FP discussions with their clients who, according to our qualitative study results, are highly trusted by their customers. A previous study showed that 70 of women visited pharmacies at least once month while 40 visited them once a week (Cairo Demographic Center, 2002).

\section{Clients' Willingness to Pay}

The majority of women who participated in our FGDs expressed willingness to pay EGP 20-30 in return for good quality FP services, while a few said they were willing to pay up to EGP 50. The last EDHS that inquired about client willingness to pay (WTP) for family planning services was EDHS 2005 which showed that 82 of participants were willing to pay twice the amount they were paying for a cycle of pills (EGP 2.0), 68 were willing to pay EGP 5.0 for a three month injectable, while 57 of women were willing to pay EGP 25.0 for an IUD. An earlier assessment of NGOs that provided FP services confirmed these findings i.e. that clients were willing to pay double the amount they were paying at NGOs (El-Zanaty and Ramadan, 2002). Moreover, a WTP validation study conducted under the FRONTIERS Operations Research Program showed that a 25 increase in the price of a Depo-Provera injection did not deter clients of the CSI project from returning to the clinic and method side effects were the main reason for discontinuation of Depo-Provera use at CSI (Bratt et al., 2005).

\section{Inclusive Policies and Regulations}

At the policy level, there are positive and encouraging messages from senior government officials regarding expanding the role of private and NGO sectors in various aspects of economic and social development. Recently, the GOE presented its "Sustainable Development Strategy: Egypt's Vision for the Year 2030". Among the salient features of the strategy are a focus on expanding the role of the private sector in the country's economic development and emphasis on greater transparency and accountability in the public sector. GOE has also promised to simplify registration procedures which deter foreign investors from starting businesses in Egypt as well as providing incentives to private sector companies meeting certain criteria such as opening the establishment in a remote area, employing a minimum of 250 employees or incorporating a minimum amount of local raw material. ${ }^{24}$ In the meantime, the government is revisiting its subsidy policies and is heading in the direction of more targeted subsidies.

24 Presidential decree number 17 (2015) 
With regards to population and FP policies, for the first time, the 2014 Egyptian Constitution acknowledges that population increase is an issue and commits the Egyptian state to implementation of a population program. The Constitution also encourages private and NGO sector participation in health service delivery and commits the state to providing social health insurance to all citizens. ${ }^{25}$ Social health insurance would obviously incorporate both for profit and not for profit providers into the system. Accreditation of private facilities may help raise standards of care offered by those providers along with reducing out of pocket spending (USAID, 2011).

Egypt's Population Strategy (2015 - 2030) developed by the National Population Council and launched by the former Prime Minister explicitly mentions the role of the private and NGO sectors as key players in reducing population growth and in improving population characteristics. ${ }^{26}$ The strategy encourages NGOs to open new clinics and recommends the implementation of an initiative whereby private clinics receive FP methods at subsidized prices in return for providing statistics on contraceptive users. Members of the NGO and FP commercial sectors were involved in the joint development of this strategy and its action plan. For NGOs, the 2014 Constitution has relaxed restrictions around their formation while protecting their autonomy by requiring a court order for their suspension. ${ }^{27}$ It is hoped that the above articles of the Constitution, national sustainable development and population strategies will be translated into effective laws that facilitate operations of the private and NGO sectors.

Moreover, in 2015 a National Contraceptive Security Committee was formed based on a ministerial decree with the aim of reviewing registration and pricing policies and estimating needs of contraceptive commodities based on population projections, client preferences and ability to pay. ${ }^{28}$ The Committee involves senior MOHP officials at Population and Family Planning, Pharmaceuticals and Procurement sectors, senior $\mathrm{Ob} / \mathrm{Gyn}$ physicians, and a representative from UNFPA. A member of the Central Administration of Pharmaceutical Affairs is currently represented on the recently formed Committee for Contraceptive Security, which is an encouraging step in the right direction.

Finally, the newly developed Reproductive Health Fellowship that is managed by MOHP provides an opportunity to create a cadre of private physicians who are interested and capable of providing quality FP services.

25 Articles 18, 36, 41, and 46 of the Egyptian Constitution (2014)

https://www.constituteproject.org/constitution/Egypt_2014.pdf

26 http://www.npc.gov.eg/

27 Article 75 of the Egyptian Constitution (2014)

${ }^{28}$ Ministerial decree number 569 (2015) 


\section{Conclusion and Recommendations}

The diminished role of the private sector in the delivery of FP is the result of a multitude of factors related to supply of FP services, demand for private services, and the social, economic, political, regulatory and donor environment. The main reasons for the decreased role of private sector in FP service delivery are discontinuation of USAID funded projects that supported the private sector, termination of MOHP training programs which often included private physicians with dual affiliation, and cessation of social marketing campaigns that promoted specific family planning methods. Moreover, government regulations on registration and pricing of family planning methods create significant disincentives for private pharmaceutical companies in the FP market and hence limit the choice of FP planning methods offered by the private sector. In addition, current laws that govern NGOs operations limit the overall availability of funds and staff for NGOs. In the meantime, improvements in the quality of services offered by the public sector have narrowed the gap between the two sectors and have inadvertently stifled growth of the private sector (USAID, 2011).

In the coming years, the financial needs of the Egyptian FP program will increase because of the increasing number of women entering into reproductive age and the overall need to increase access to and effective use of FP methods despite reductions in donor assistance. Increasing access to FP services will require leveraging the role of different groups of service providers. This includes promoting the role of pharmacists in dispensing methods and increasing the role of NGOs as many of them are well-positioned to reach out to marginalized communities (e.g. those in slum areas).

Appropriate policies and strategies are needed to mobilize all potential sources of FP provision, including commercial and NGO sectors, and to identify the clientele that each sector is best positioned to serve. The MOHP needs more effective mechanisms in place to target its resources to poor FP clients and to take action in providing an enabling policy environment for participation of NGO and commercial sectors.

The following recommendations could strengthen the role of the private sector as it complements the government's current and planned efforts to meet population demand for contraception.

\section{Adopt a Total Market Approach (TMA)}

Egypt's FP program should adopt a total market approach whereby the comparative advantage of all sectors (public, private commercial and NGO or donor-financed social marketing) is leveraged to ensure equitable access to family planning (Brady et al., 2016; Pollard, 2007). Today, the MOHP is inadvertently subsidizing 34 of women from the highest (fourth and fifth) wealth quintiles who are using public services. Use of subsidized services by middle and upper class women represents an unnecessary burden on meager government resources.

The target group for each of the three sectors needs to be well defined, for example: the MOHP targets those who live in remote rural and low income urban areas, NGO clinics target lower middle class women, private doctors target middle and upper class women while pharmacists target all groups of women and possibly men. Mobile clinics that provide free FP services should be restricted to neighborhoods or villages that are deprived of both public and private services. In addition, a voucher program could be pilot tested in areas where government FP services are currently not available or accessible whereby poor women receive subsidized service at the private sector. In the Frontier Governorates, 57 of the population receives their FP services from private providers. In these regions, contraceptive choice among low-income households may be constrained by their limited ability to pay for FP methods, especially the IUD, at private facilities. 


\section{Create Demand for Private FP Services}

The private sector (pharmaceutical companies, private physicians, pharmacists and NGOs providing FP services) should create demand for its services through social marketing campaigns that specifically target young couples, those in the upper two wealth quintiles and those who live in urban areas. In fact, social marketing is an FP High Impact Practice that has proven effective both in Egypt as well as in other countries (USAID, 2013). Less expensive media (e.g. women's magazines) could be used to advertise and raise awareness about specific FP methods. Also, innovative communication channels such as social media and mobile technology should be explored. Secondary analysis of EDHS showed that 90 of women with demand for FP have their own cell phone and 20 have smart phones. Social marketing could also target youth at universities, youth centers and factories as a strategy to "prepare the market" before they get married. NGOs should explore opportunities for subcontracting with organizations that employ a high percentage of women (e.g. garment factories); provide FP awareness-raising in those venues and refer women who are interested in FP to their facilities. As has been done in Bangladesh and other industrializing middle-income countries, targeted work-based contraceptive services can expand opportunity to young women employed in industrial settings. In fact, the Evidence Project is currently conducting an implementation research project that targets female factory workers in Cambodia through on-site FP counseling and referral to designated private facilities.

\section{Capitalize on All Opportunities to Counsel Women (and their Husbands) about FP}

Private physicians should counsel women during ANC, PNC and child health care visits about the benefits of birth spacing, risks associated with repeated and closely spaced pregnancies, and explain to them various contraceptive options. Physicians should also identify other health services that women of reproductive age seek on a regular basis and integrate family planning counseling into those services.

\section{Educate Physicians and Pharmacists About New FP Methods}

To increase sales of FP methods, pharmaceutical companies need to increase awareness of new brands of FP methods among physicians and pharmacists and address any misconceptions related to those methods. Pharmaceutical companies could reach doctors and pharmacists through brochures, newsletters, medical representatives as well as at professional conferences. Moreover, they should offer training workshops for physicians and pharmacists so they can stay abreast of new developments in contraceptive technology. They should especially prioritize the training of private physicians in insertion and removal of IUD and subdermal implants.

\section{Make Private Sector Services More Attractive to Clients}

In a competitive market, the private sector needs to demonstrate to potential clients that it is offering better quality services that justify higher price. NGOs need to enforce use of service delivery guidelines to ensure minimum standards of quality, while doctors and pharmacists must more proactively seek new information about FP methods and enhancement of their own skills. Private physicians and NGO clinics could also consider offering extended hours as well as additional services to attract more clients (e.g. breast or cervical cancer screening). Pharmacist assistants and clerks, because of their lack of training, should not be allowed to counsel customers about contraceptives or medications.

\section{Ensure Method Availability and Expand Method Choice}

The current registration and importation procedures and pricing policies for FP methods should be revisited by MOHP. Committees that are assigned to review registration papers for a new FP commodity should involve FP experts as well as representatives of the Population and FP Sector of MOHP. The list of reference countries for importation of FP commodities should be expanded to allow new producers to enter the 
Egyptian market. ECPs and women controlled barrier methods are very much needed to prevent unintended pregnancy especially among women who have infrequent sex (e.g. whose husbands are travelling) thus registration and licensing procedures for those methods need to be relaxed. In the meantime, long term reversible FP methods need to be made available for current users who do not want to have more children. Restrictions on provision of Implanon and three month injectables by private sector providers limit its accessibility to a large segment of women who do not want to use public services. The private sector should be allowed to provide Implanon after ensuring that providers have been adequately trained in insertion and removal techniques. Fast track release of imported FP shipments should be considered to prevent method stock-outs. Additional research is needed to test the acceptability and use effectiveness of new FP methods that could be introduced to the Egyptian market (e.g. Standard Days Method, Sino-Implant, Sayana Press and contraceptive vaginal ring). In fact, the introduction of IUD and three month injectables in Egypt in the late 80s was associated with a 10 point increase in contraceptive prevalence rate between 1988 and 1992 (Robinson and El-Zanaty, 2006).

\section{Support the Creation of More Private Sector Outlets for Clients}

The NGO sector should be encouraged to grow and to fill the gap in remote and underserved areas. The MOSS should consider easing procedures and accelerating review of registration and approvals for NGOs to receive funding. Also, the MOHP should continue to provide subsidized contraceptives to NGOs and should work out a mutually acceptable mechanism for secondment of physicians to NGOs. Meanwhile, physicians should seek innovative mechanisms to increase their revenues (e.g. by introducing new services) and by working in the afternoon and evenings so as not to conflict with MOHP service hours. International agencies could provide institutional capacity building to NGOs to assist them in introducing more revenue generating activities, marketing their services and pricing their services to better match their clients' ability to pay for them. The RH Fellowship Program should be strengthened, scaled up and a clear career path for its graduates should be developed to encourage more physicians to join the program. In the meantime, mechanisms to assist graduates of the program in setting up their own private practice should be explored (e.g. through use of medical credit funds).

\section{Create Linkages Among Private Sector Providers}

Pharmacists play a critical role in the distribution of contraceptives in Egypt. In some governorates, pharmacies are the most frequent source of modern contraceptives in the private sector, more so than private medical clinics. A branded network that links pharmacists and private doctors (e.g. a revitalized Ask - Consult network) could serve as a platform for reaching both groups of health care providers; strengthening their capacity; and ensuring high quality of services and mutually beneficial referral of clients between both groups of providers. For example, through such a network, pharmacists could refer customers to qualified physicians for medical consultation before dispensing a FP method or for management of side effects while, on the other hand, physicians could refer their patients who would like oral pills, injectables, ECP or condoms to pharmacists in the same network. Additionally, the network could serve as a platform for communication with the MOHP and other government agencies (e.g. MOSS, Ministry of Industry and Trade). International donors and technical assistance organizations could assist in the establishment of the network, while small fees paid by physician and pharmacist members of the network would help to ensure its sustainability.

\section{Integrate FP and Contraceptive Technology into Medical and Pharmacy School Curricula}

Undergraduate training for medical and pharmacy students should include expanded information on various FP methods, healthy timing and spacing of pregnancy and linkages between FP, maternal and child health. Also, programs for house officers and $\mathrm{Ob} / \mathrm{Gyn}$ residents should include practical training in FP counseling, IUD and implants insertion and removal. 


\section{Foster Public-Private Partnerships}

The relationship between the private and public sectors needs to be more complementary than competitive. Insufficient cooperation and dialogue among private and public sector entities may lead to inefficiencies and increase the potential for duplication and overlap among private and public sector efforts and, as a result, will contribute to the neglect of other areas (Health Systems 20/20 Project, 2012). MOHP should make all FP methods available to the private sector (including three-month injectables and subdermal implants) in return for the timely provision of adequate statistics and good quality services in the private sector. For example, to ensure quality insertion and removal services, those who provide such services should be required to provide a certificate issued by an accredited FP training institution denoting their competency in insertion and removal.

On the other hand, the private sector should support the MOHP by providing high quality services to the poor and underprivileged. Rather than focusing on methods that they produce, pharmaceutical companies could provide FP training in all FP methods to physicians affiliated with the MOHP and most of whom have their own private practices. As a result, their products would be promoted to both the private and public sector through the same provider. Moreover, pharmaceutical companies could take advantage of privileges offered to MOHP on public TV and satellite channels by jointly sponsoring media campaigns with MOHP to promote specific FP methods. Both public and private sectors should understand that each new client who has her FP needs met through quality services and choice, is a gain to the FP program regardless of where she received her FP method. 


\section{References}

Ahmed K., M. El-Fiki, P. Friel and J. Schuller-Repp. 2010. Assessment of the Logistics System for Contraceptives. Cairo: UNFPA and Ministry of Health

Armand F., O’Hanlon B., McEuen M., Kolyada L., and Levin L. March 2007. Private Sector Contribution to Family Planning and Contraceptive Security in the Europe and Eurasia Region. Bethesda, MD: Private Sector Partnerships-One project, Abt Associates Inc.

Barnes, Jeffrey, Janet Vail, and Dawn Crosby. 2012. Total Market Initiatives for Reproductive Health. Bethesda, MD: Strengthening Health Outcomes through the Private Sector Project, Abt Associates.

Bratt, John; Nahla Abdel-Tawab; Magdy Abdel-Kader; and Mohamed Edrees. 2005. "Willingness-to-Pay for Services Provided by the Clinical Services Improvement Project (CSI) in Egypt”. FRONTIERS Final Report. Cairo: Population Council.

Brady C, Weeden L, Hutchings J., Parks, J. 2016. "Planning Guide for a Total Market Approach to Increase Access to Family Planning. Module 1: Landscape Assessment.” Seattle, WA: PATH and Washington, DC: The Population Council, Evidence Project.

Cairo Demographic Center. 2002. Promoting the Role of the Private Sector as a Source of Family Planning Services and Products. Cairo: Cairo Demographic Center and Research Management Unit - National Population Council.

Central Agency for Public Mobilization and Statistics (CAPMAS) (Egypt) and Minnesota Population Center. 2011. "Egypt General Census for Population, Housing, and Establishments 2006.” Integrated Public Use. Microdata Series, International: Version 6.1 [Machine-readable database]. Minneapolis: University of Minnesota.

Central Agency for Public Mobilization and Statistics (CAPMAS). 2014. Census of Economic Establishments. Cairo: CAPMAS

Central Agency for Public Mobilization and Statistics (CAPMAS). 2016. Statistics. (Available in Arabic) at: http://capmas.gov.eg/Pages/IndicatorsPage.aspx?page_id=6149\&ind_id=1116; http://capmas.gov.eg/Pages/IndicatorsPage.aspx?page_id=6149\&ind_id=1116

El-Saharty S., Richardson G. and Chase S. 2005. Egypt and the millennium development goals challenges and opportunities. Washington D.C.: The World Bank.

El-Zanaty and Associates, Ministry of Health and Population and UNFPA. 2011. Study on Reproductive Health Impact of Family Health Model Pilots in Egypt. Available at: http://egypt.unfpa.org/english/publication/1828cf97-c4b3-46bb-b5fa-d845a127ca8f

El-Zanaty F. and Ramadan H. 2002. The Potential for Non-governmental family Planning / Reproductive Health Clinics for Providing Quality Services. Cairo: El-Zanaty and Associates and Research Management Unit - National Population Council.

Fateem, E. and Wahba, M. 2012. The Study of Reproductive Health Information, Attitudes and Practices of Bedouin Youth. Final Report. Cairo: The Egyptian Family Health Society. 
Gwatkin, D., Bhuiya, A., and Victora, C. 2004. Making health systems more equitable. Lancet 364: 1273-80.

Hafez Z., Oraby D. and Soliman C., Qualitative Assessment of Youth Friendly Clinics. Family Health International and UNFPA, 2008. Cairo: Family Health International

Health Systems 20/20 Project. 2012. Assessment of Family Planning Program. Bethesda, MD: Health Systems 20/20 project, Abt Associates Inc.

Krafft C., 2015. "Educational Experiences of Youth in Egypt: Who attends School, who succeeds, and who struggles". In: Rania Roushdy and Maia Sieverding (eds) Panel Survey of Young People in Egypt (SYPE) 2014. Generating Evidence for policy, programs and research. Cairo: Population Council

Marek, T., O’Farrell, C., Yamamoto, Ch., Zable, I., et al. 2005. Trends and Opportunities in Public- private Partnerships to Improve Health Service Delivery in Africa. Africa Region Human Development Working Paper Series. Human Development Sector, Africa Region, The World Bank. Washington D.C.: The World Bank.

Ministry of Health and Population, El-Zanaty Associates, and ORC Marco. 2005. Egypt Service Provision Assessment Survey 2004. Calverton, Maryland, USA: Ministry of Health and Population and ORC Macro.

Ministry of Health and Population [Egypt], El-Zanaty and Associates [Egypt] and ICF International. 2015. Egypt Demographic and Health Survey 2014. Cairo, Egypt and Rockville, Maryland, USA: Ministry of Health and Population and ICF International.

Ministry of Health and Population [Egypt], El-Zanaty and Associates [Egypt], and ICF International. 2015. Egypt Health Issues Survey 2015. Cairo, Egypt and Rockville, Maryland, USA: Ministry of Health and Population and ICF International.

Ministry of Population. 2015. Egypt Population Strategy 2015-2030. (In Arabic). Cairo: National Population Council.

Nakhimovsky, S, Douglas Glandon, Nadwa Rafeh, Nagwan Hassan. November 2011. Egypt National Health Accounts: 2008/09. Bethesda, MD: Health Systems 20/20 project, Abt Associates Inc.

National Population Council. 2015. Quarterly Statistical Report on Family Planning Services (July September 2015). (In Arabic). Cairo: National Population Council.

Nawar, L.; Kharboush, I.; Ibrahim, M.; Makhlouf, H.; and Adamchak, S. 2004. Impact of Improved ClientProvider Interaction on Women's Achievement of Fertility Goals. FRONTIERS Final Report. Cairo: Population Council.

Pollard, R. 2007. Social marketing: An introduction to the total market approach to commodities and services supply in low-income countries. Paper presented at the George Washington University Health Communication and Social Marketing Symposium Series; Washington, DC.

Rabie, Tamer; Boehmova, Zuzana; Hawkins, Loraine; Abdel-Tawab, Nahla ; Saher, Sally; El Shitany, Atef. 2013. Transforming Family Planning Outlook and Practice in Egypt: A Rights-Based Approach. Washington, DC: World Bank. 
Ravenholt B. 1991. Potential for increased involvement of the private sector in family planning services delivery in Egypt: Initial assessment. Cairo: USAID.

Robinson W., and El-Zanaty F, 2006. The Demographic Revolution in Modern Egypt. Lanham, MD: Lexington Books.

Sieverding M. and Ragab A., 2015." Marriage and Family Formation Trends among Youth in Egypt" In: Rania Roushdy and Maia Sieverding (eds) Panel Survey of Young People in Egypt (SYPE) 2014. Generating Evidence for policy, programs and research. Cairo: Population Council.

UNICEF and Informal Settlements Development Facility, Egypt (2013), Multidimensional Child Poverty in Slums and Unplanned Areas in Egypt. Cairo: UNICEF Egypt and ISDF. United Nations Development Program (UNDP) 2012. Assessment of Development Results: Egypt. Cairo: UNDP.

United Nations Development Programme (UNDP) and the Ministry of Planning, Monitoring and Administrative Reform. 2015. Egypt's Progress towards Millennium Development Goals.

United States Agency for International Development (USAID) 2011. Egypt Health and Population Legacy Review: Volume I. Washington, DC: USAID. Available at: http://pdf..usaid.gov/pdf_docs/PDACS570.pdf

USAID; 2013 High Impact Practices in Family Planning (HIP). Social marketing: leveraging the private sector to improve contraceptive access, choice, and use Washington, DC: USAID Available at: http://www.fphighimpactpractices.org/resources/social-marketing-leveraging-privatesectorimprove-contraceptive-access-choice-and-use

U.S. Census Bureau, 2004. International Population Reports WP/02,Global Population Profile: 2002. Washington, DC: U.S. Government Printing Office. 


\section{Appendix I | Characteristics of Study Participants}

\section{A. CHARACTERISTICS OF PROVIDERS WHO PARTICIPATED IN IN-DEPTH INTERVIEWS}

\begin{tabular}{|c|c|c|c|c|c|c|c|c|}
\hline \multirow{2}{*}{$\begin{array}{l}\text { Variable } \\
\text { Category }\end{array}$} & \multirow{2}{*}{$\begin{array}{l}\text { Median } \\
\text { age }\end{array}$} & \multicolumn{2}{|c|}{ Sex } & \multicolumn{2}{|c|}{ Location } & \multirow[t]{2}{*}{ Education } & \multicolumn{2}{|c|}{ Place of work } \\
\hline & & $\mathbf{M}$ & $\mathbf{F}$ & Urban & Rural & & NGO & Private for profit \\
\hline $\begin{array}{l}\text { Physicians } \\
(\mathrm{N}=18)\end{array}$ & 50 & 7 & 11 & 14 & 4 & $\begin{array}{c}\text { MBBCh (3) } \\
\text { Diploma (4) } \\
\text { Master (9) } \\
\text { Doctorate (2) }\end{array}$ & 8 & 10 \\
\hline $\begin{array}{l}\text { Pharmacists } \\
\qquad(\mathrm{N}=12)\end{array}$ & 36 & 6 & 6 & 9 & 3 & $\begin{array}{l}\text { Bachelor (10) } \\
\text { Master (1) } \\
\text { Doctorate (1) }\end{array}$ & & 12 \\
\hline
\end{tabular}

\section{B. CHARACTERISTICS OF WOMEN WHO PARTICIPATED IN FGDS}

\begin{tabular}{|c|c|c|c|c|c|c|c|}
\hline \multirow{2}{*}{$\begin{array}{r}\text { Variable } \\
\text { Governorate }\end{array}$} & \multirow{2}{*}{$\begin{array}{c}\text { Median } \\
\text { age }\end{array}$} & \multicolumn{2}{|c|}{ Location } & \multirow[t]{2}{*}{ Education } & \multirow[t]{2}{*}{ Employment } & \multirow{2}{*}{$\begin{array}{l}\text { No. of } \\
\text { Children }\end{array}$} & \multirow{2}{*}{$\begin{array}{c}\text { Previous } \\
\text { method used }\end{array}$} \\
\hline & & Urban & Rural & & & & \\
\hline $\begin{array}{c}\text { Cairo } \\
2 \text { FGDs } \\
(\mathrm{N}=16)\end{array}$ & 32 & $\begin{array}{c}8 \\
\text { Informal } \\
\text { urban } \\
\text { (8 women) }\end{array}$ & & $\begin{array}{c}\text { Illiterate (1) } \\
\text { Elementary } \\
\quad(7) \\
\text { Secondary (7) } \\
\text { University (1) }\end{array}$ & $\begin{array}{l}\text { Not working } \\
\text { for cash (10) } \\
\text { Working for } \\
\text { cash (2) }\end{array}$ & $\begin{array}{c}1 \text { child (3) } \\
2 \text { children }(2) \\
3+\text { children } \\
(11)\end{array}$ & $\begin{array}{c}\text { Pills (6) } \\
\text { IUD (7) } \\
\text { Monthly } \\
\text { injection (1) } \\
3 \text { month } \\
\text { injection (2) } \\
\text { Implanon (0) } \\
\text { Condoms (0) }\end{array}$ \\
\hline $\begin{array}{l}\text { Gharbeya } \\
4 \text { FGDs } \\
(\mathrm{N}=34)\end{array}$ & 30 & $\begin{array}{l}2 \text { FGDs } \\
16 \text { women }\end{array}$ & $\begin{array}{c}2 \text { FGDs } \\
18 \\
\text { women }\end{array}$ & $\begin{array}{c}\text { Illiterate }(2) \\
\text { Read \& write } \\
(2) \\
\text { Elementary } \\
(9) \\
\text { Secondary } \\
(18) \\
\text { Institute/Uni } \\
\text { versity (3) }\end{array}$ & $\begin{array}{l}\text { Not working } \\
\text { for cash (24) } \\
\text { Working for } \\
\text { cash }(10)\end{array}$ & $\begin{array}{c}1 \text { child (9) } \\
2 \text { children } \\
\text { (13) } \\
3+\text { children } \\
\text { (12) }\end{array}$ & $\begin{array}{c}\text { Pills (9) } \\
\text { IUD (23) } \\
\text { Monthly } \\
\text { injection (0) } \\
3 \text { month } \\
\text { injection (2) } \\
\text { Implanon (0) } \\
\text { Condoms (0) }\end{array}$ \\
\hline $\begin{array}{l}\text { Assiut } \\
4 \text { FGDs } \\
(\mathrm{N}=40)\end{array}$ & 30 & $\begin{array}{l}2 \text { FGDs } \\
20 \text { women }\end{array}$ & $\begin{array}{c}2 \text { FGDs } \\
20 \\
\text { women }\end{array}$ & $\begin{array}{c}\text { Illiterate (14) } \\
\text { Read \& write } \\
\quad(2) \\
\text { Elementary } \\
\quad(5) \\
\text { Secondary } \\
(13) \\
\text { Institute/Uni } \\
\text { versity (5) }\end{array}$ & $\begin{array}{l}\text { Not working } \\
\text { for cash (37) } \\
\text { Working for } \\
\text { cash (3) }\end{array}$ & $\begin{array}{c}1 \text { child (6) } \\
2 \text { children }(9) \\
3+\text { children } \\
(25)\end{array}$ & $\begin{array}{c}\text { Pills (22) } \\
\text { IUD (7) } \\
\text { Monthly } \\
\text { injection (0) } \\
3 \text { months } \\
\text { injections (9) } \\
\text { Implanon (0) } \\
\text { Condoms (0) } \\
\text { LAM (2) }\end{array}$ \\
\hline
\end{tabular}




\section{Appendix II | Buying and Selling Prices of Contraceptives Sold at Public Sector29}

\begin{tabular}{|c|c|c|}
\hline Method & Buying price (EGP) & Selling prices (EGP) \\
\hline IUD Copper T380A & 3.0 & 2.0 \\
\hline $\begin{array}{c}\text { 3-month injectable } \\
\text { (Depo-Provera) }\end{array}$ & 7.0 & 1.0 \\
\hline Male condom & 0.20 & 0.10 \\
\hline POP-Levonor & 2.9 & 1.0 \\
\hline COC-Microcept & 1.17 & 0.65 \\
\hline Implanon & $85.0^{30}$ & 5.0 \\
\hline
\end{tabular}

29 Table adapted from Ahmed, K. et al. 2010

${ }^{30}$ Original price of Implanon is equivalent to EGP 185 but has been reduced by MSD in response to FP2020 Initiative. http://www.merckresponsibility.com/wp-content/uploads/2015/08/IMPLANON_STATEMENT.pdf 


\section{Appendix III | List of Contraceptive Methods Available at Public, Private and NGO Sectors and their Prices}

\begin{tabular}{|c|c|c|c|}
\hline \multirow[b]{2}{*}{ Method } & \multicolumn{3}{|c|}{ Price } \\
\hline & MOHP facilities & Private pharmacies & NGO sector \\
\hline Combined oral pills & 65 P.T. / packet of 21 pills & 65 P.T. - EGP $39.0^{31}$ & EGP 1.0 \\
\hline Progestin-only pills & $\begin{array}{l}\text { EGP } 1.0 \text { per packet of } 28 \\
\text { pills }\end{array}$ & EGP 10.0-22.0 & EGP 2.0 \\
\hline Copper T IUD & EGP 2.0 & EGP 15.0-36.0 & EGP $17.0^{32}$ \\
\hline Mirena ${ }^{\circledR}$ (LNG - IUS) & NA & EGP 700 & NA \\
\hline Three-month injectable & EGP 1.0 per injection & NA & EGP 10.033 \\
\hline Monthly injectable & EGP 2.0 per injection & EGP 5.0 & \\
\hline $\begin{array}{l}\text { Subdermal implants } \\
\text { (Implanon) }\end{array}$ & EGP 5.0 & $\mathrm{NA}$ & NA \\
\hline Male condoms & EGP 1.0 for a pack of 10 & EGP $4.5-22.0$ & $\begin{array}{c}\text { EGP } 2.0 \text { for a pack } \\
\text { of } 10^{35}\end{array}$ \\
\hline Vaginal suppositories ${ }^{36}$ & EGP 1.5 for a pack of 6 & EGP 39.0 & NA \\
\hline Emergency contraceptive pills & NA & EGP 4.5 & NA \\
\hline Consultation fees & $\begin{array}{l}\text { No fees if before } 12 \text { noon, } \\
\text { otherwise EGP } 1.0\end{array}$ & No fees & EGP 10.0-45.0 \\
\hline
\end{tabular}

31 Various brands of locally manufactured and imported combined pills are available at private pharmacies

32 This price includes insertion fees.

33 This price includes consultation fees.

34 Implants are only offered in Urban Health centers where a trained Ob/Gyn specialist is available.

35 Some NGO clinics do not have male condoms.

36 Not found in most MOHP clinics as MOHP has stopped requesting them due to low demand. 


\section{Appendix IV | Brands of FP Methods Available at Commercial Sectors and Their Prices ${ }^{37}$}

\begin{tabular}{|l|c|}
\hline \multicolumn{1}{|c|}{ Method and brand } & Commercial sector price (EGP) \\
\hline IUD & 15.0 \\
\hline $\begin{array}{l}\text { U-Kare Copper T 375 } \\
\text { Pregna DKT }\end{array}$ & 10.0 \\
\hline $\begin{array}{l}\text { Copper T 380A w/Safe Load } \\
\text { DKT }\end{array}$ & 700 \\
\hline Mirena & \\
\hline Male condom & 0.34 \\
\hline Fiesta and Sutra (DKT) & \\
\hline Injectables & 8.5 \\
\hline Depo-Provera (DKT) & 5.0 \\
\hline 1-month injectable (Misocept) & \\
\hline Progestin-only pills (POP) & 7.75 \\
\hline Exluton (DKT) & 10.0 \\
\hline Microlut & 20.0 \\
\hline Cirazet & \\
\hline Combined pills (COC) & 0.65 \\
\hline Microcept & 2.25 \\
\hline Triocept & 22.5 \\
\hline Cilest & 25.0 \\
\hline Gynera & 15.0 \\
\hline Marvelon & 39.0 \\
\hline Yasmeen & 4.5 \\
\hline Emergency Contraceptive Pills & \\
\hline Contraplan & \\
\hline & \\
\hline
\end{tabular}

37 Table adapted from Ahmed, K. et al. 2010. 


\title{
Appendix V | List of Reference Countries
}

\author{
Ministry of Health \\ Central Administration for \\ Pharmaceutical Affairs \\ General Registration Department \\ Technical Committee
}
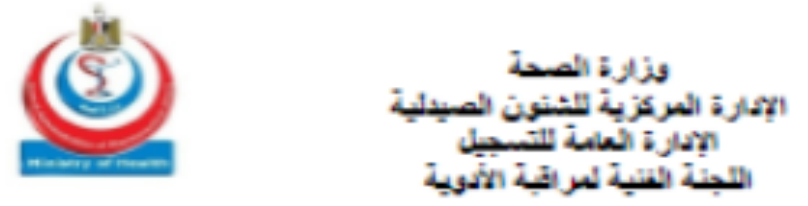

List of Reference Countries approved

by technical committee 31/12/2009
1. Australia
2. Austria
3. Belgium
4. Canada
5. Denmark
6. Germany
7. Finland
8. Iceland
9. France
10. Ireland
11. Luxemburg
12. Holland
13. Newzeland
14. Norway
15. Sweden
16. Switzerland
17. USA
18. UK
19. Japan
20. Italy
21. Spain
22. Portugal

Tel. $+202-23684288+202-23640368+202-23640368$ Ext:201 Fax: $+202-23684194$

Website: www.edamohp.gov.eg Version: 01 Email: technical a eda.mohp.gor.eg 


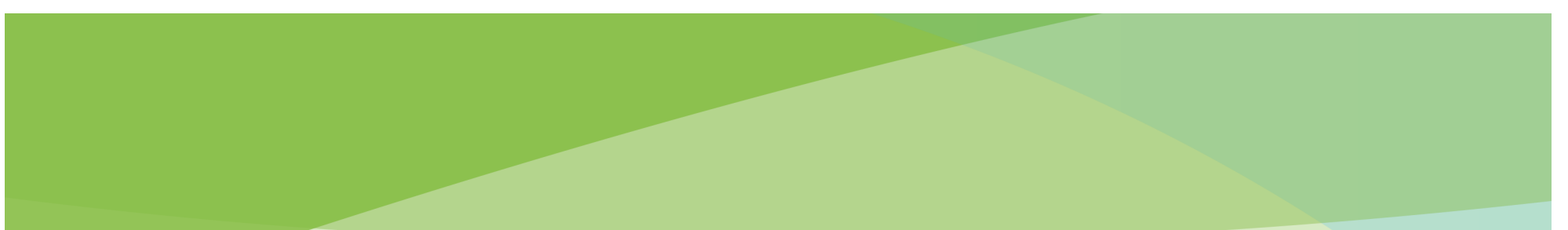

\section{The Evidence Project}

Population Council

4301 Connecticut Avenue, NW, Suite 280

Washington, DC 20008 USA

tel +12022379400

evidenceproject.popcouncil.org 